\title{
Human habenula segmentation using myelin content
}

Citation for published version (APA):

Kim, J., Naidich, T. P., Ely, B. A., Yacoub, E., De Martino, F., Fowkes, M. E., Goodman, W. K., \& Xu, J. (2016). Human habenula segmentation using myelin content. Neuroimage, 130, 145-156.

https://doi.org/10.1016/j.neuroimage.2016.01.048

Document status and date:

Published: 15/04/2016

DOI:

10.1016/j.neuroimage.2016.01.048

Document Version:

Publisher's PDF, also known as Version of record

\section{Please check the document version of this publication:}

- A submitted manuscript is the version of the article upon submission and before peer-review. There can be important differences between the submitted version and the official published version of record.

People interested in the research are advised to contact the author for the final version of the publication, or visit the DOI to the publisher's website.

- The final author version and the galley proof are versions of the publication after peer review.

- The final published version features the final layout of the paper including the volume, issue and page numbers.

Link to publication

\footnotetext{
General rights rights.

- You may freely distribute the URL identifying the publication in the public portal. please follow below link for the End User Agreement:

www.umlib.nl/taverne-license

Take down policy

If you believe that this document breaches copyright please contact us at:

repository@maastrichtuniversity.nl

providing details and we will investigate your claim.
}

Copyright and moral rights for the publications made accessible in the public portal are retained by the authors and/or other copyright owners and it is a condition of accessing publications that users recognise and abide by the legal requirements associated with these

- Users may download and print one copy of any publication from the public portal for the purpose of private study or research.

- You may not further distribute the material or use it for any profit-making activity or commercial gain

If the publication is distributed under the terms of Article $25 \mathrm{fa}$ of the Dutch Copyright Act, indicated by the "Taverne" license above, 


\title{
Human habenula segmentation using myelin content
}

\author{
Joo-won Kim a,b,*, Thomas P. Naidich ${ }^{\text {b,c,d }}{ }^{\text {, }}$, Benjamin A. Ely ${ }^{\mathrm{e}}$, Essa Yacoub ${ }^{\mathrm{f}}$, Federico De Martino ${ }^{\mathrm{g}}$, \\ Mary E. Fowkes ${ }^{\text {h }}$, Wayne K. Goodman ${ }^{\text {e,i }}$, Junqian $\mathrm{Xu}^{\mathrm{a}, \mathrm{b}, \mathrm{e}, \mathrm{f}, *}$ \\ a Translational and Molecular Imaging Institute, Icahn School of Medicine at Mount Sinai, New York, NY, USA \\ ${ }^{\mathrm{b}}$ Department of Radiology, Icahn School of Medicine at Mount Sinai, New York, NY, USA \\ c Department of Neurosurgery, Icahn School of Medicine at Mount Sinai, New York, NY, USA \\ ${ }^{d}$ Department of Pediatrics, Icahn School of Medicine at Mount Sinai, New York, NY, USA \\ e Department of Neuroscience, Icahn School of Medicine at Mount Sinai, New York, NY, USA \\ ${ }^{\mathrm{f}}$ Center for Magnetic Resonance Research, Department of Radiology, University of Minnesota, Minnesota, MN, USA \\ ${ }^{g}$ Department of Cognitive Neurosciences, Faculty of Psychology and Neuroscience, Maastricht University, Netherlands \\ h Department of Pathology, Icahn School of Medicine at Mount Sinai, New York, NY, USA \\ i Department of Psychiatry, Icahn School of Medicine at Mount Sinai, New York, NY, USA
}

\section{A R T I C L E I N F O}

\section{Article history:}

Received 20 October 2015

Accepted 20 January 2016

Available online 27 January 2016

\section{Keywords:}

Habenula

Subcortical segmentation

Myelin-sensitive image

Myelin map

Region growing

Geometric constraints

Partial volume estimation

\begin{abstract}
A B S T R A C T
The habenula consists of a pair of small epithalamic nuclei located adjacent to the dorsomedial thalamus. Despite increasing interest in imaging the habenula due to its critical role in mediating subcortical reward circuitry, in vivo neuroimaging research targeting the human habenula has been limited by its small size and low anatomical contrast. In this work, we have developed an objective semi-automated habenula segmentation scheme consisting of histogram-based thresholding, region growing, geometric constraints, and partial volume estimation steps. This segmentation scheme was designed around in vivo $3 \mathrm{~T}$ myelin-sensitive images, generated by taking the ratio of high-resolution T1w over T2w images. Due to the high myelin content of the habenula, the contrast-to-noise ratio with the thalamus in the in vivo $3 \mathrm{~T}$ myelin-sensitive images was significantly higher than the T1w or T2w images alone. In addition, in vivo $7 \mathrm{~T}$ myelin-sensitive images (T1w over T2* $\mathrm{w}$ ratio images) and ex vivo proton density-weighted images, along with histological evidence from the literature, strongly corroborated the in vivo $3 \mathrm{~T}$ habenula myelin contrast used in the proposed segmentation scheme. The proposed segmentation scheme represents a step toward a scalable approach for objective segmentation of the habenula suitable for both morphological evaluation and habenula seed region selection in functional and diffusion MRI applications.
\end{abstract}

(c) 2016 Elsevier Inc. All rights reserved.

\section{Introduction}

The habenula $(\mathrm{Hb})$, a pair of highly conserved epithalamic nuclei (Aizawa et al., 2011; Bianco and Wilson, 2009), plays a central role in mediating the midbrain monoamine nuclei underlying subcortical reward circuitry (Hikosaka et al., 2008; Hikosaka, 2010; Proulx et al., 2014). The left and right $\mathrm{Hb}$ are connected by the habenular commissure (Kim, 2009), located just superior to the posterior commissure (PC), and can be divided into functionally distinct lateral $\mathrm{Hb}(\mathrm{LHb})$ and medial $\mathrm{Hb}(\mathrm{MHb})$ portions (Hikosaka et al., 2008). These can be further divided into several subnuclei based on cellular morphological features (Díaz et al., 2011). The LHb has gained increasing attention due to its interneuron-mediated inhibition of the ventral tegmental area (VTA), downregulating mesolimbic reward activity across a range

* Corresponding authors at: One Gustave L. Levy Place, Box 1234, New York, NY 100296574, USA. Fax: + 16465379689.

E-mail addresses: joo-won.kim@mssm.edu (J.-W. Kim), junqian.xu@mssm.edu (J. Xu). of animal models (Geisler and Trimble, 2008; Matsumoto and Hikosaka, 2007, 2009; Proulx et al., 2014). Other midbrain LHb projections indirectly inhibit the dopaminergic substantia nigra pars compacta (Geisler and Trimble, 2008) and serotonergic dorsal raphe nuclei (Meye et al., 2013). The MHb serves a similar role in modulating activity of the interpeduncular nucleus (Viswanath et al., 2014), further influencing monoamine signaling (Nishikawa et al., 1986). The Hb thus exerts substantial influence to the subcortical reward and mood systems.

Morphologically, reduced postmortem $\mathrm{Hb}$ volume has been documented in depression (Ranft et al., 2010) and may be especially pronounced in people with major depressive disorder (MDD) (Savitz et al., 2011b). Recent case reports from two treatment-resistant MDD patients describe symptom improvements following deep brain stimulation (DBS) targeting the $\mathrm{Hb}$ (Kiening and Sartorius, 2013; Sartorius et al., 2010), supporting the proposed link between $\mathrm{Hb}$ dysfunction and MDD. Given its functional importance and potential role in psychiatric disorders, accurate localization and segmentation of the $\mathrm{Hb}$ in neuroimaging studies is important for morphological evaluation, DBS 
targeting (Sartorius and Henn, 2007), and seed region selection in both functional magnetic resonance imaging (fMRI) (Lawson et al., 2014; Hennigan et al., 2015; Erpelding et al., 2014; Ely et al., under revision) and diffusion magnetic resonance imaging (dMRI) (Shelton et al., 2012; Strotmann et al., 2014).

To date, however, in vivo imaging of the human $\mathrm{Hb}$ has been a challenge. The $\mathrm{Hb}$ is a small structure, reported as approximately $32 \mathrm{~mm}^{3}$ per hemisphere in postmortem histology (Ranft et al., 2010), and borders the third ventricle and dorsomedial thalamus just superior to the PC and anterior to the pineal gland. Most anatomical MRI studies have manually defined the $\mathrm{Hb}$ by exploiting its slight hyperintensity relative to the surrounding tissue in $\mathrm{T} 1$-weighted (T1w) images (Savitz et al., 2011a, 2011b; Carceller-Sindreu et al., 2015). Histologically, this T1w hyperintensity reflects the high myelin content of the $\mathrm{Hb}$, originating from the terminating and passing white matter fibers of the afferent stria medullaris (SM), originating fibers of the efferent fasciculus retroflexus (FR), bilateral connecting fibers of the habenular commissure, and small myelinated fibers distributed throughout the Hb (Díaz et al., 2011). Unfortunately, such manual segmentation approaches are inherently subjective.

Recently, Lawson et al. proposed a geometric approach to triangulate the $\mathrm{Hb}$ region based on anatomical landmarks (Lawson et al., 2013), which they used to define the $\mathrm{Hb}$ in a follow-up fMRI study (Lawson et al., 2014). While reasonable as a means of choosing fMRI seed regions, their approach defines the lateral boundaries separating the $\mathrm{Hb}$ from the thalamus based on the manual selection of a landmark, the mesopontine junction, a few centimeters away from the Hb. Consequently, $\mathrm{Hb}$ segmentation results from this method are less appropriate for morphological evaluation than those based on manual $\mathrm{Hb}$ segmentation from T1w images (Savitz et al., 2011a, 2011b; Carceller-Sindreu et al., 2015).

Recently, pioneering high-resolution quantitative in vivo and ex vivo $7 \mathrm{~T}$ imaging studies of the $\mathrm{Hb}$ have showed lower $\mathrm{T} 1$ and T2* values in the $\mathrm{Hb}$ than the surrounding thalamic tissue (Strotmann et al., 2014). Attempt has also been made to use ultra-high-resolution $(60 \mu \mathrm{m})$ ex vivo $\mathrm{T} 1$ and $\mathrm{T}_{2} *$ maps to classify $\mathrm{Hb}$ subdivisions (Strotmann et al., 2013). Although quantitative imaging at ultra-high field is a promising approach for $\mathrm{Hb}$ research, the limited number of cases in these pilot studies prevented a generalizable quantification of contrast-to-noise ratio (CNR). Moreover, previous literature has not addressed the possibility of automated segmentation based on clear $\mathrm{Hb}$ contrast in widely available anatomical images at lower field strengths.

In this study, we propose an objective semi-automated $\mathrm{Hb}$ segmentation scheme based on local MRI signal properties within and around the $\mathrm{Hb}$ to yield segmentation results suitable for both morphological evaluation and $\mathrm{Hb}$ seed region selection in fMRI and dMRI studies. We used a combination of T1w and T2-weighted (T2w) anatomical images to improve the CNR for segmentation. It should be noted that the term "T2w image" is a radiological convention; the contrast in these images actually derives mainly from variations in tissue T1, proton density, and magnetization transfer effects if slice-selective radio frequency (RF) pulses are used (Glasser et al., 2014). Recent studies have described substantial gains in sensitivity to subtle myelin content differences through the use of "myelin maps" generated by taking the ratio of aligned T1w and T2w images (Glasser and Van Essen, 2011). In light of the ongoing debate over the exact myeloarchitectural interpretation of these T1w/T2w images, we will refer to them as "myelin-sensitive images" hereafter in this manuscript. This technique has so far been primarily applied to cortical imaging, particularly for improved discrimination of areal boundaries (Glasser et al., 2014; Shafee et al., 2015). In this study, we have extended the concept of the myelin-sensitive images to enhance subcortical $\mathrm{Hb}$ myelin contrast for objective $\mathrm{Hb}$ segmentation in in vivo $3 \mathrm{~T}$ neuroimaging studies. Additionally, we have obtained in vivo $7 \mathrm{~T}$ myelin-sensitive images and ex vivo proton density-weighted (PDw) images of $\mathrm{Hb}$ tissue samples to corroborate the in vivo $3 \mathrm{~T} \mathrm{Hb}$ myelin contrast.

\section{Methods}

Image acquisition

In vivo $3 T$

Anatomical data were obtained from fifty unrelated healthy subjects (age $=29.5 \pm 3.7$ years, 27 female) randomly selected from the public WU-Minn Human Connectome Project (HCP) 500 Subjects Release (Van Essen et al., 2012). The HCP structural acquisition protocol has been detailed previously (Glasser et al., 2013). Briefly, 0.7-mm isotropic resolution T1 $\mathrm{w}$ and $\mathrm{T} 2 \mathrm{w}$ images were acquired with a 32-channel head coil on the WU-Minn 3 T HCP Connectom Skyra (Siemens, Erlangen, Germany) with TR/TE/TI $=2400 / 2.14 / 1000 \mathrm{~ms}$, flip angle $(\mathrm{FA})=8^{\circ}$ for T1w acquisition, and TR/TE $=3200 / 565 \mathrm{~ms}$ for T2w acquisition.

\section{In vivo $7 \mathrm{~T}$}

Images originally acquired from six healthy subjects (median age $=$ 32 years) at $7 \mathrm{~T}$ for an auditory cortex study were reanalyzed. As described in the previously published study (De Martino et al., 2015), $0.6 \mathrm{~mm}$ isotropic resolution $\mathrm{T} 1 \mathrm{w}$ - and $\mathrm{T}^{*}$-weighted $\left(\mathrm{T} 2^{*} \mathrm{w}\right)$ images were acquired with a 24-channel head coil on an actively shielded $7 \mathrm{~T}$ whole body Siemens Magnetom scanner (Erlangen, Germany) with $\mathrm{TR} / \mathrm{TE} / \mathrm{TI}=3100 / 3.5 / 1500 \mathrm{~ms}, \mathrm{FA}=5^{\circ}$ for T1 $\mathrm{w}$ acquisition, and TR/ $\mathrm{TE}=4910 / 16 \mathrm{~ms}, \mathrm{FA}=8^{\circ}$ for $\mathrm{T} 2^{*} \mathrm{w}$ acquisition.

\section{Ex vivo $7 T$}

Two axial sections (about $80 \times 72 \times 40 \mathrm{~mm}^{3}$ and $95 \times 88 \times 15 \mathrm{~mm}^{3}$, respectively) of midbrain tissue containing the $\mathrm{Hb}$ were collected from two males ( 73 and 68 years) who had died of heart diseases. The tissues were fixed in formalin for more than 2 weeks, transferred to phosphatebuffered saline for storage, and immersed in perfluoropolyether (Fomblin, Solvay Solexis, NJ) before imaging. For each of the samples, 3D spoiled gradient recalled echo (GRE) PDw images were acquired for approximately $60 \mathrm{~h}$ with a 32-channel head coil (Nova Medical, Wilmington, MA) on an actively shielded $7 \mathrm{~T}$ whole body Siemens Magnetom scanner (Erlangen, Germany) at $200 \mu \mathrm{m}$ isotropic resolution, $\mathrm{TR} / \mathrm{TE}=9.5 / 3.47 \mathrm{~ms}, \mathrm{FA}=6^{\circ}$, generating 164 (224 slices) and 384 (96 slices) averages, respectively.

\section{In vivo image processing}

All HCP 3 T data were pre-processed with the HCP PreFreeSurfer pipeline (Glasser et al., 2013) for gradient non-linearity distortion correction, anterior commissure (AC)-posterior commissure (PC) alignment, and T2w to T1w image registration. Two sets of final images were calculated, with and without bias field correction [i.e., dividing each voxel intensity by an approximated bias field (BiasField_acpc_ dc.nii.gz), the square root of the product of T1w and T2 $\mathrm{w}$ intensities, $\sqrt{T 1 w \times T 2 w}$, for Hb-thalamus CNR comparison. Myelin-sensitive images were generated by taking the ratio of aligned T1w to T2w (Glasser and Van Essen, 2011) or T1w to T2*w (De Martino et al., 2015) for in vivo $3 \mathrm{~T}$ (Fig. 1) and in vivo $7 \mathrm{~T}$ (Fig. 2) data, respectively.

\section{In vivo 3 T habenula segmentation}

The overall $\mathrm{Hb}$ segmentation scheme from in vivo $3 \mathrm{~T}$ highresolution structural (T1w and T2w) images (Fig. 3) consists of five steps: (i) region of interest (ROI) initialization, (ii) histogram-based thresholding, (iii) region growing, (iv) geometric constraints, and (v) partial volume estimation. The segmentation software, implemented in python, can be downloaded from https://github.com/junqianxulab/ habenula_segmentation. 


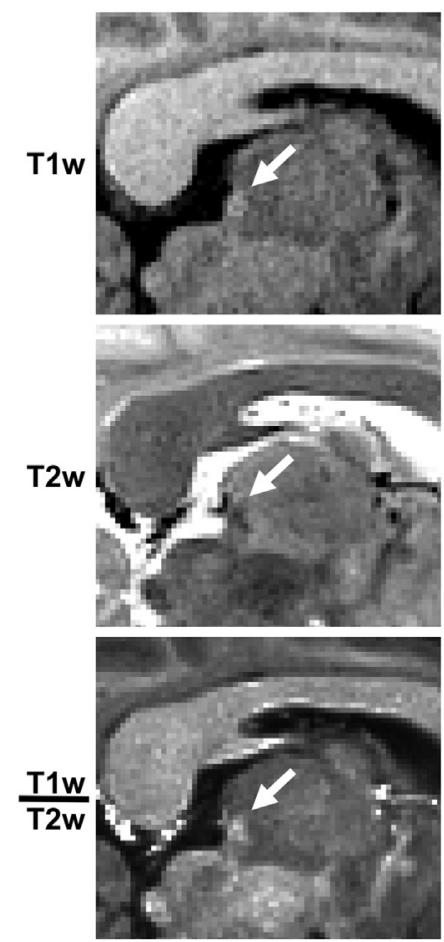

Sagittal
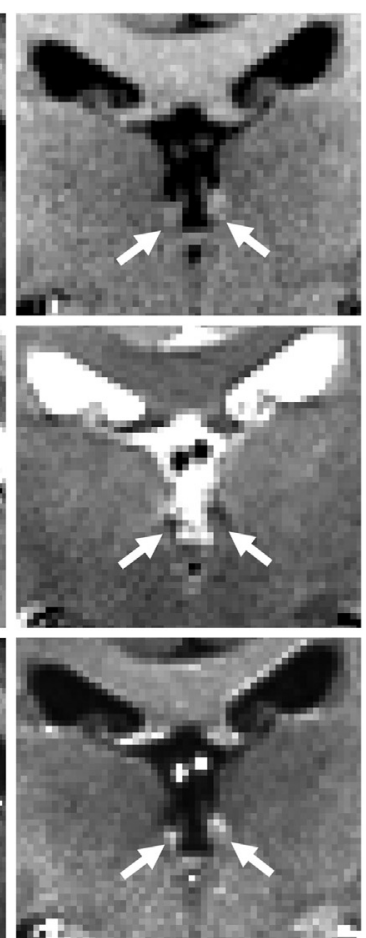

Coronal
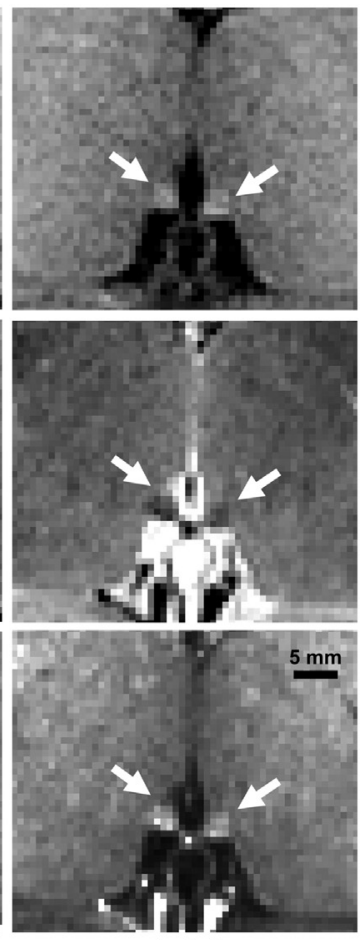

Axial

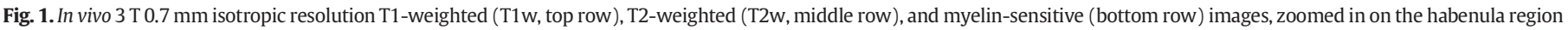
(white arrows), from a representative subject. Left, middle, and right column contain sagittal, coronal, and axial views, respectively.

\section{Region of interest initialization}

Starting from a manually chosen seed voxel within the $\mathrm{Hb}$, a sphereshaped permissive ROI large enough to contain voxels completely surrounding the Hb was initialized (see Appendix A). This step was performed for both the left and right $\mathrm{Hb}$, resulting in two potentially overlapping spherical ROIs (Fig. 3B, yellow outlines).

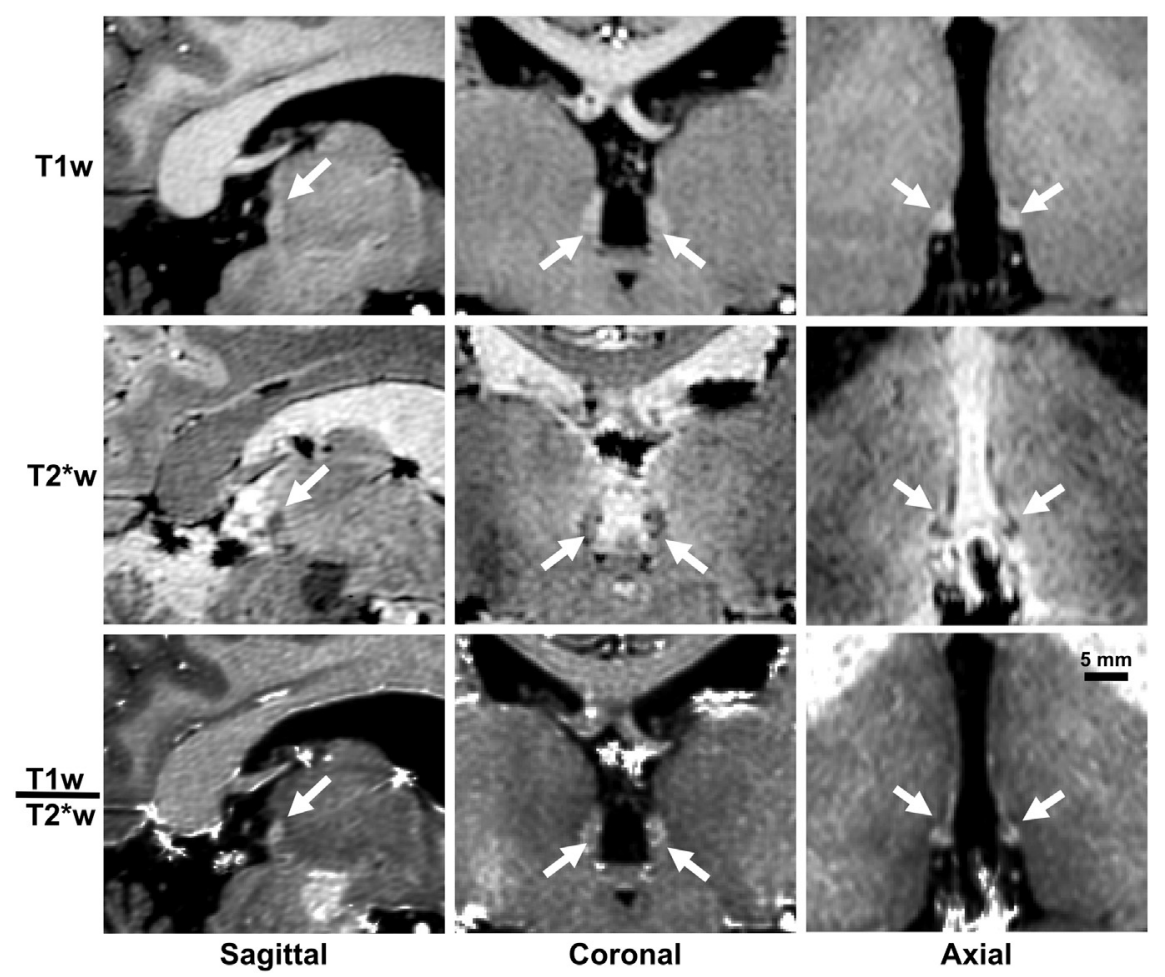

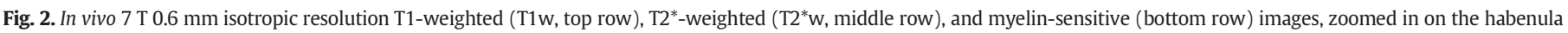
region (white arrows), from a representative subject. Left, middle, and right column contain sagittal, coronal, and axial views, respectively. 

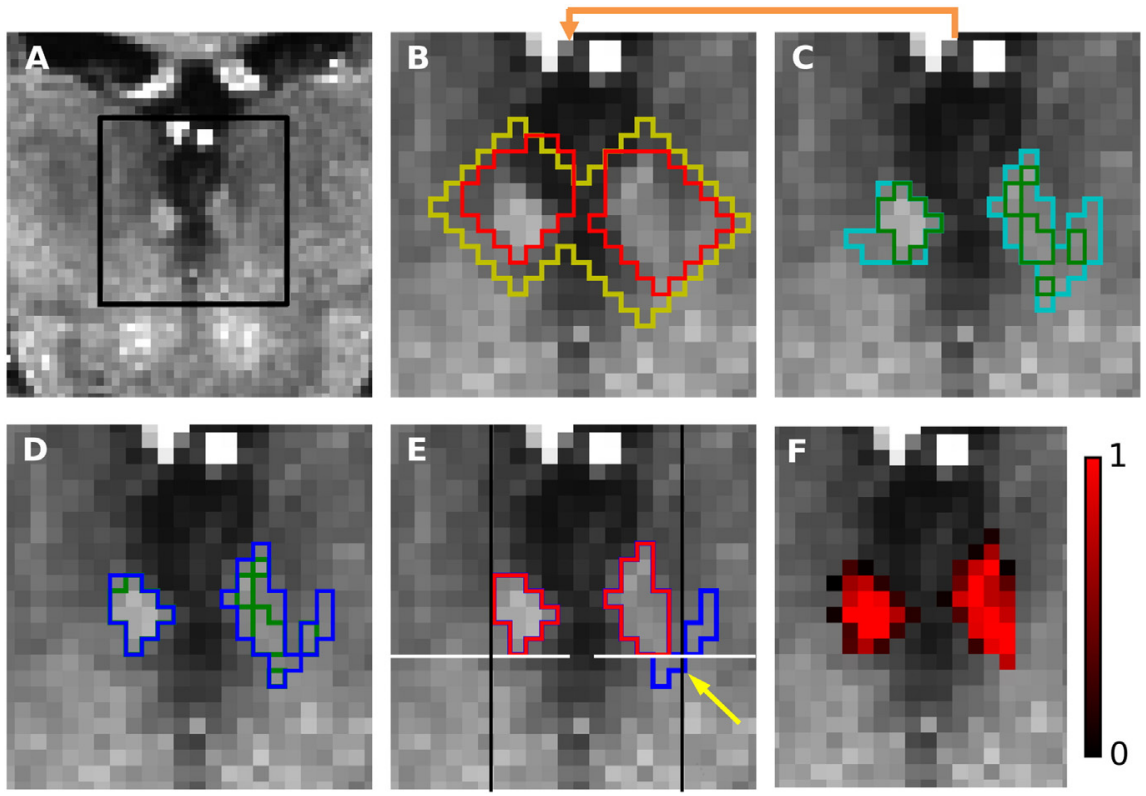

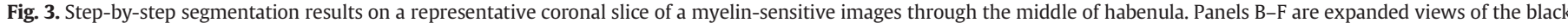

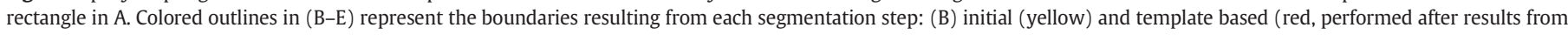

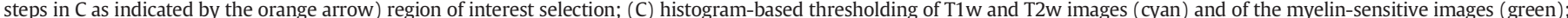

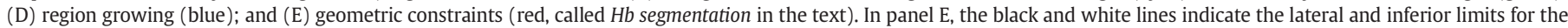

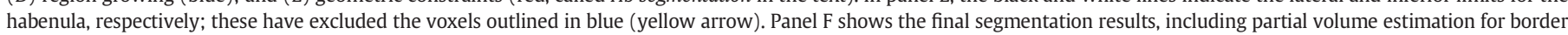
voxels (brighter red represents greater portion of habenula). A myelin-sensitive image thresholding value of $\alpha=0.9$ was used for this example [Eq. (2)].

\section{Histogram-based thresholding}

In order to restrict the initial ROIs to more tightly surround the $\mathrm{Hb}$, histogram-based intensity thresholding was applied. Intensity histograms from in vivo T1w and T2w human brain images usually follow a multimodal distribution due to heterogeneous tissue components. As the high myelin content of the $\mathrm{Hb}$ (Fig. 4) typically results in hyperintensity in T1w (Fig. 1, top row) and hypointensity in T2w (Fig. 1, middle row) images, Gaussian curves were fit to the most prominent peaks of the T1w and T2w intensity histograms (see Inline Supplementary Figure S1A and C, respectively). Specifically, the intensity ranges of these peaks were defined as

$$
\begin{aligned}
& {\left[\operatorname{mode}_{\mathrm{T} 1 \mathrm{w}}-\frac{\max _{\mathrm{T} 1 \mathrm{w}}-\text { mode }_{\mathrm{T} 1 \mathrm{w}}}{2}, \max _{\mathrm{T} 1 \mathrm{w}}\right] \text { and }} \\
& {\left[0, \operatorname{mode}_{\mathrm{T} 2 \mathrm{w}}+\frac{\max _{\mathrm{T} 2 \mathrm{w}}-\text { mode }_{\mathrm{T} 2 \mathrm{w}}}{2}\right]}
\end{aligned}
$$

for the T1w and T2w histograms, respectively. After defining the means $(\mu)$ and standard deviations $(\sigma)$ within these intensity $(I)$ ranges by Gaussian fitting, voxels in the initial ROIs not meeting the thresholding criteria indicated in Eq. (1) were excluded:

$I_{\mathrm{T} 1 \mathrm{w}}>\mu_{\mathrm{T} 1 \mathrm{w}}-2 \sigma_{\mathrm{T} 1 \mathrm{w}}$ and $I_{\mathrm{T} 2 \mathrm{w}}<\mu_{\mathrm{T} 2 \mathrm{w}}+2 \sigma_{\mathrm{T} 2 \mathrm{w}}$

Inline Supplementary Fig. S1 can be found online at http://dx.doi. org/10.1016/j.neuroimage.2016.01.048.

This served to exclude mostly cerebral spinal fluid (CSF) voxels. After applying this first-pass thresholding, the T1w and T2w image intensity histograms of the remaining voxels were fitted again to Gaussian distributions (see Inline Supplementary Figure S1B and D) to define $\mu^{\prime}{ }_{\mathrm{T} 1 \mathrm{w}}, \sigma^{\prime}{ }_{\mathrm{T} 1 \mathrm{w}}, \mu^{\prime}{ }_{\mathrm{T} 2 \mathrm{w}}$, and $\sigma^{\prime}{ }_{\mathrm{T} 2 \mathrm{w}}$. Similar to the firstpass thresholding, voxels not meeting the thresholding criteria indicated in Eq. (2) were excluded:

$I_{\mathrm{T} 1 \mathrm{w}}>\mu_{\mathrm{T} 1 \mathrm{w}}^{\prime}, \quad I_{\mathrm{T} 2 \mathrm{w}}<\mu_{\mathrm{T} 2 \mathrm{w}}^{\prime}$, and $I_{\mathrm{Myelin}}>\frac{\mu_{\mathrm{T} 1 \mathrm{w}}^{\prime}+\alpha \sigma_{\mathrm{T} 1 \mathrm{w}}^{\prime}}{\mu_{\mathrm{T} 2 \mathrm{w}}^{\prime}-\alpha \sigma_{\mathrm{T} 2 \mathrm{w}}^{\prime}}$,
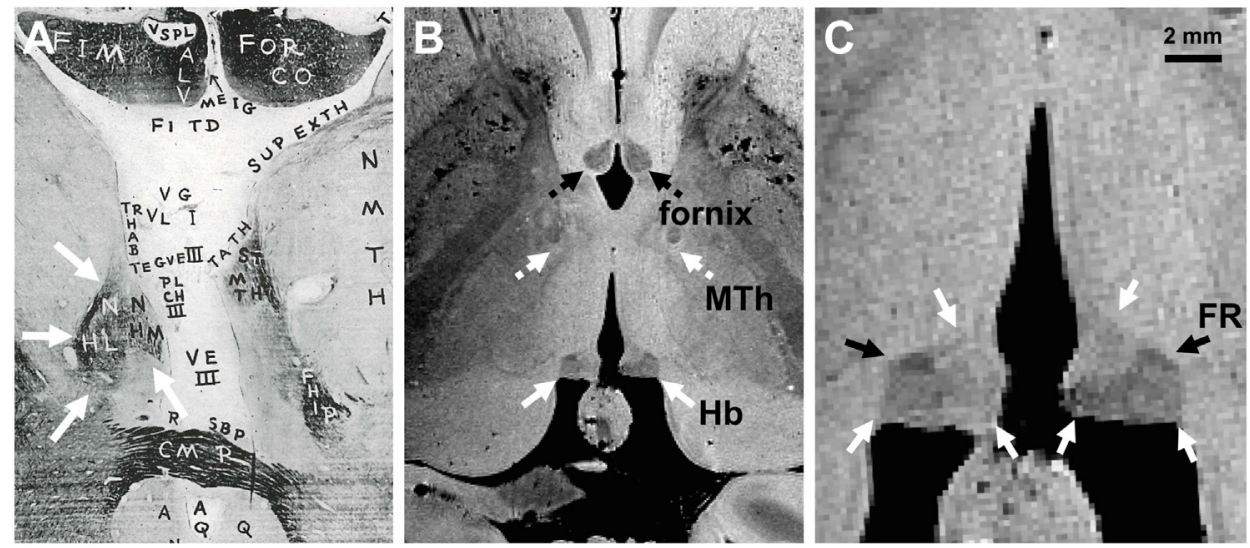

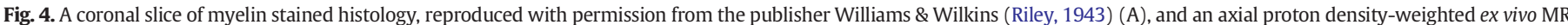

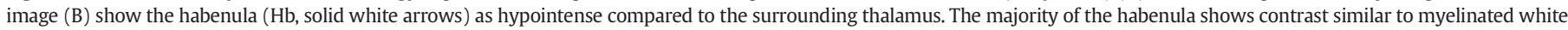

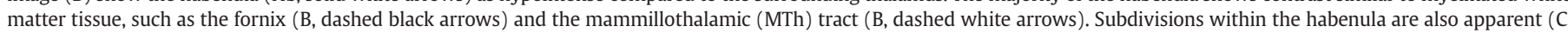
expanded from B). The most hypointense region within habenula reflects the emergence of fasciculus retroflexus (FR) fibers (C, black arrows). 
where $\alpha$ is a constant (Fig. 3C, cyan color from T1w and T2w intensity thresholding, green color from myelin-sensitive intensity thresholding indicated in Eq. (2)). This second-pass thresholding refines the results from the first step by applying more conservative T1w and T2w thresholds and further restricts the resulting $\mathrm{Hb}$ voxels by adding a myelinsensitive image intensity threshold. Among these thresholding criteria in the second-pass, the most influential is the myelin-sensitive image intensity threshold. As this depends on the $\alpha$ value, we systematically evaluated the $\mathrm{Hb}$ segmentation results for a range of $\alpha$ values (see Myelin-sensitive image threshold constant $\alpha$ section). An $\alpha$ value of 0.9 was empirically chosen for all other evaluations in this manuscript.

The initial ROI and intensity thresholding depend heavily on the locations of the manually chosen Hb seed voxels. To decrease this sensitivity and improve robustness, left and right center of mass voxels resulting from the previous two steps were used as new seed voxels, from which updated left and right ROIs were formed based on a $\mathrm{Hb}$ template ROI (Appendix B). The thresholding steps were repeated using these new $\mathrm{Hb}$ template-shaped ROIs (Fig. 3B, red outlines). The resulting voxels are called thresholded $\mathrm{Hb}$ regions in the following sections.

\section{Region growing}

To reduce the between-subject bias of $\alpha$, the optimal value of which may differ across subjects, a region growing method was used. Since the intensity differences between $\mathrm{Hb}$ and CSF voxels are typically large enough to be independent of $\alpha$ values, this method was only performed between the thresholded $\mathrm{Hb}$ voxels and the surrounding thalamus voxels; values were calculated for left and right $\mathrm{Hb}$ regions independently. From a voxel $v$ of intensity $I_{v}$ to a region $R$, the intensity distance $d_{I}(v, R)$ is defined as

$d_{I}(v, R)=\frac{\left|I_{v}-\mu_{R}\right|}{\sigma_{R}}$,

where $\mu_{R}$ is the mean and $\sigma_{R}$ is the standard deviation of intensities in $R$. A thalamus (Thal) ROI was defined as the voxels within the updated $\mathrm{Hb}$ template-shaped ROI with an $L_{1}$ distance (i.e., rectilinear distance) of less than three voxels to any thresholded $\mathrm{Hb}$ voxel and that met the T1w and T2w intensity threshold criteria in Eq. (1). Note that consequently, the thalamus ROI changes whenever $\mathrm{Hb}$ region changes. Starting with the thresholded $\mathrm{Hb}$ regions from the previous step, each boundary voxel $v$ in $\mathrm{Hb}$ or Thal was assigned to $\mathrm{Hb}$ only if $d_{I}(v, \mathrm{Hb})<d_{I}(v$, Thal $)$. This step was iterated a maximum of 10 times or until convergence, meaning no exchange of $\mathrm{Hb}$ or Thal voxel assignments (Fig. 3D, blue outlines).

\section{Geometric constraint}

In order to correct for overestimation of the $\mathrm{Hb}$ region in the previous steps (Fig. 3E, blue outline), mainly due to the ambiguity of the $\mathrm{Hb}$ boundary near the FR (Fig. 4C, black arrows) and with the thalamus laterally, geometric constraints were applied. Such an approach is consistent with previous work by Lawson et al. (2013), who performed segmentation on coronal slices using several geometric constraints near the $\mathrm{Hb}$ presumed invariant across subjects.

One of the geometric constraints used by Lawson et al. was a horizontal line $x$ (see Lawson et al., 2013, Fig. 2), representing the inferior limit of $\mathrm{Hb}$ right above the habenular commissure. We adopted this constraint but implemented the horizontal line without manually defining the intersection between the medial boundary of the $\mathrm{Hb}$ and the posterior/habenular commissure (point A in Lawson et al., 2013, Fig. 2). Anatomically, the medial boundary of the $\mathrm{Hb}$ for a given horizontal line in a coronal slice is next to CSF. We therefore set a criterion for the medial boundary of the Hb voxels to be within two voxels of CSF voxels; this value was chosen empirically to account for partial volume effects. Voxels were defined as CSF if they had a T1w intensity less than $\mu_{\mathrm{T} 1 \mathrm{w}}-2 \sigma_{\mathrm{T} 1 \mathrm{w}}$ from Eq. (1). The most inferior row satisfying the above criterion defined an inclusive horizontal line as the inferior limit of $\mathrm{Hb}$ voxels in the coronal slice (Fig. 3E, white lines).

Another geometric constraint used by Lawson et al. was a line $z$ (see Lawson et al., 2013, Fig. 2) between the superior aspect of the $\mathrm{Hb}$ and the lateral aspect of the mesopontine junction, used to define the boundary between the $\mathrm{Hb}$ and thalamus, which shows no concaveness based on histology or in published atlases (Riley, 1943; Mai et al., 2007; Hawrylycz et al., 2012). To avoid manually selecting a heuristic landmark (point C in Lawson et al., 2013, Fig. 2), we set a criterion, based on the morphology of the $\mathrm{Hb}$, that the inferior-superior coordinate of the most superior voxel in each column of Hb voxels in a coronal slice should monotonically decrease as the column moves laterally. The most lateral column satisfying this second criterion defines an inclusive vertical line as the lateral limit of the $\mathrm{Hb}$ voxels in the coronal slice (Fig. 3E, black line; Appendix C). The resulting voxels are called $\mathrm{Hb}$ segmentation (Fig. 3E, red outlines) in the following sections. All $\mathrm{Hb}$ segmentation results from HCP in vivo 3 T MR images were visually inspected by an expert neuroanatomist (TPN) together with two experienced researchers (JWK and JX).

\section{Partial volume estimation}

As the size of the habenula is small, typically more than two thirds of the Hb voxels from previous steps were boundary voxels. Hence, partial volume estimation was applied to allow a better approximation of the segmented habenula volume. The partial volume of each voxel inside and outside the $\mathrm{Hb}$ boundary was determined using the myelin-sensitive images alone due to its CNR advantage over T1w or T2w images (Fig. 6). Estimation was based on each boundary voxel's intensity difference from its neighboring voxels, which included faces, edges, and vertices, giving a maximum of 26 neighboring voxels. Note that every boundary voxel necessarily had neighboring voxels inside and outside the $\mathrm{Hb}$. The partial volume of a boundary voxel is defined as $\frac{I_{v}-M_{\text {out }}}{M_{\text {in }}-M_{\text {out' }}}$ where $I_{v}$ is the myelin-sensitive image intensity of the boundary voxel, while $M_{\text {in }}$ and $M_{\text {out }}$ are mean myelin-sensitive image intensities of the neighboring voxels inside and outside of the $\mathrm{Hb}$, respectively. After assigning partial volume values to all boundary voxels and complete volumes to all inside voxels, the $\mathrm{Hb}$ volume was calculated in units of $\mathrm{mm}^{3}$. These combined $\mathrm{Hb}$ segmentation and boundary voxels (Fig. 3F) and their corresponding volumes are called $\mathrm{Hb}$ segmentation with partial volume estimation in the following sections.

\section{Habenula-thalamus contrast-to-noise ratio (CNR)}

We evaluated the Hb-thalamus CNRs among T1w, T2w, and myelinsensitive images with and without bias field correction. The $\mathrm{Hb}$ signal intensity for calculating CNR was the mean intensity of the $\mathrm{Hb}$ segmentation before partial volume estimation (results from the Geometric constraint section). The thalamus signal intensity was the mean intensity of any voxels that were within two voxels of any $\mathrm{Hb}$ segmentation voxels, with CSF voxels excluded by applying Eq. (2). In the CNR calculations, the absolute difference between habenula and thalamus intensity was used as contrast (i.e., numerator), while the standard deviation of the thalamus voxel intensities was used as noise (i.e., denominator).

\section{Signal intensity correlation}

In order to evaluate systematic variations in $\mathrm{T} 1 \mathrm{w}, \mathrm{T} 2 \mathrm{w}$, and myelinsensitive image intensities, we manually defined representative anatomical regions around the $\mathrm{Hb}$ with relatively uniform $\mathrm{T} 1 \mathrm{w}$ image intensities for pairwise signal intensity correlations. Regions selected included the head of the caudate nuclei, splenium of the corpus callosum (CCs), and CSF (see Inline Supplementary Figure S5B).

Inline Supplementary Fig. S5 can be found online at http://dx.doi. org/10.1016/j.neuroimage.2016.01.048. 


\section{Gamma distribution}

To investigate the heterogeneity of myelin-sensitive image intensities in the segmented $\mathrm{Hb}$, we fit the myelin-sensitive image intensity histograms to the gamma distribution:

$\frac{\left(x-x_{0}\right)^{k-1} \mathrm{e}^{-\left(x-x_{0}\right) / \theta}}{\theta^{k} \Gamma(k)}$,

where $\Gamma(k)$ is the gamma function, $x$ is the myelin-sensitive image intensity values, and $k$ (shape) and $\theta$ (scale) are the parameters to be fit. For the fitting, we set $x_{0}$ to the minimum intensity in the histogram and ran a least squares curve-fitting module [optimize.curve_fit using the default convergence tolerance and maximum iteration, in SciPy Python library 0.14.0 (SciPy, 2001)] to determine the values of $k$ and $\theta$ for each subject.

\section{MNI space transformation}

To approximate the location of the $\mathrm{Hb}$ in standard atlas space, $\mathrm{Hb}$ segmentation regions were binarized and transformed to the Montreal Neurological Institute brain template (MNI152) using the non-linear transformations ( $a c p c \_d c 2$ standard.nii.gz) incorporated into the HCP PreFreeSurfer pipeline. These transformed $\mathrm{Hb}$ segmentation regions were averaged to yield a single image representing a probabilistic map of $\mathrm{Hb}$ in the MNI152 space (see MNI space transformation in Results section).

\section{Statistical analysis}

Paired $t$-tests (two-tailed) were performed to compare the habenula-thalamus CNRs in T1w, T2w, and myelin-sensitive images. Pairwise Pearson correlations between the $\mathrm{Hb}$, caudate, CCs, and CSF regions were calculated for $\mathrm{T} 1 \mathrm{w}, \mathrm{T} 2 \mathrm{w}$, and myelin-sensitive image intensities to evaluate systematic image intensity variations. All statistical tests were performed using R version 3.2.1 (R Core Team, 2015).

\section{In vivo and ex vivo $7 \mathrm{~T}$ data manual segmentation}

To validate our approach, we compared the segmented $\mathrm{Hb}$ volumes from $3 \mathrm{~T}$ in vivo images with manually segmented in vivo and ex vivo $7 \mathrm{~T}$ data, as these allowed for higher spatial resolution and CNR. The $\mathrm{Hb}$ boundaries were defined based on image hyperintensity (for in vivo 7 T myelin-sensitive images) or hypointensity (for ex vivo PDw images) by an expert neuroanatomist (TPN) together with two experienced researchers (JWK and JX). Manual segmentation was facilitated by the more conspicuous $\mathrm{Hb}$ contrast of in vivo $7 \mathrm{~T}$ myelin-sensitive images and ex vivo $7 \mathrm{~T}$ PDw images relative to in vivo $3 \mathrm{~T}$ myelin-sensitive images (see Inline Supplementary Figure S4).
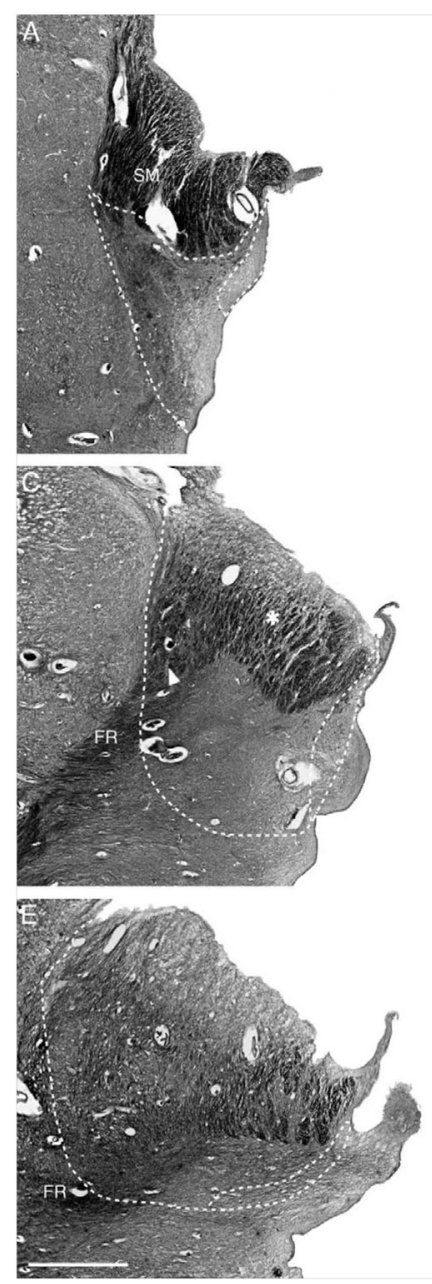
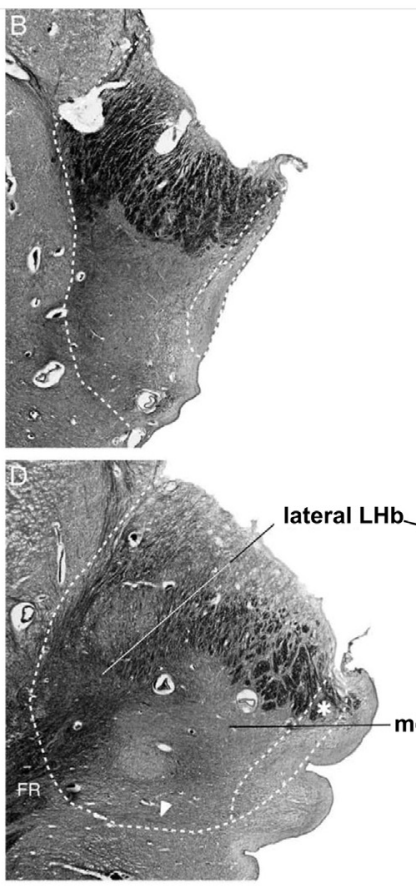

F

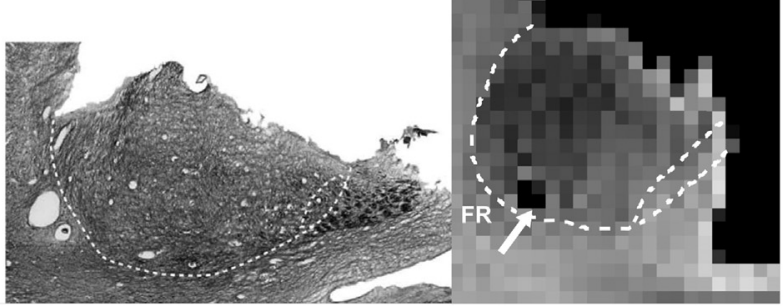

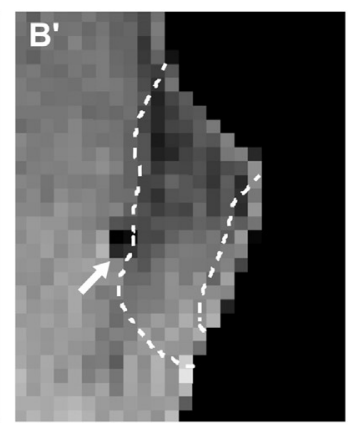
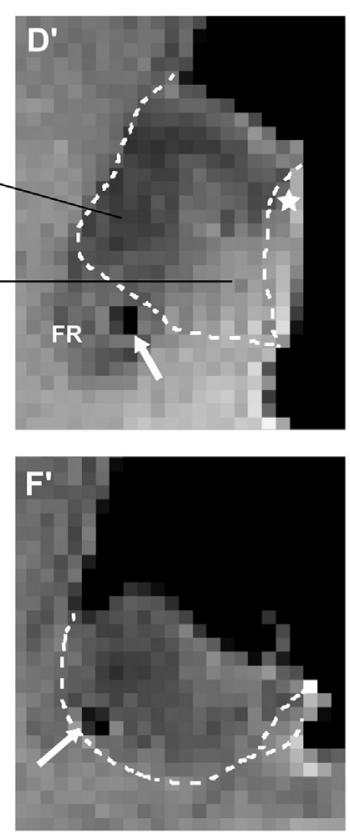

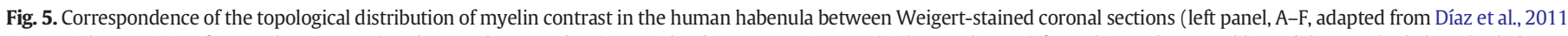

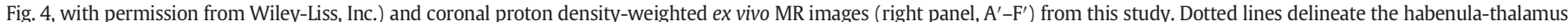

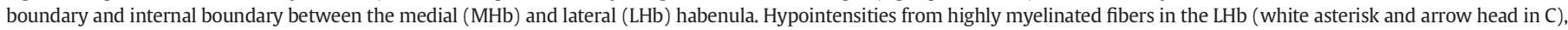

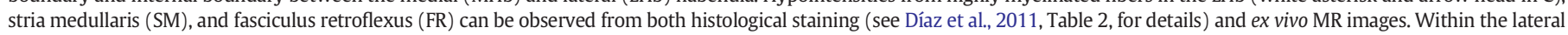
habenula, greater myelination is evident for the lateral than medial aspect (D). White arrows in the MRI images ( $\left.\mathrm{B}^{\prime}-\mathrm{F}^{\prime}\right)$ indicate artifacts due to tissue damage. 
Inline Supplementary Fig. S4 can be found online at http://dx.doi. org/10.1016/j.neuroimage.2016.01.048.

\section{Results}

Myelin contrast in ex vivo image and histology

Representative axial sections of the ex vivo PDw image confirm the habenula myelin contrast (Fig. 4B) but reveals substantial heterogeneity within the habenula (Fig. 4C). Comparison between the habenula myelin contrast from histology in the literature (Fig. 5 left panel, A-F) and ex vivo PDw images (Fig. 5 right panel, $\mathrm{A}^{\prime}-\mathrm{F}^{\prime}$ ) demonstrates close topological correspondence between the MR image contrast and the distribution of myelinated fibers in the habenula (Díaz et al., 2011).

\section{Habenula segmentation results}

A representative successful segmentation result is shown in Fig. 6 . All but one of the segmentation results from the 50 subjects were deemed reasonable by the expert neuroanatomist (TPN). Follow-up comparison with other successful segmentation cases and ex vivo MRI data revealed that the one failed case was probably due to voxels of the FR being assigned to the $\mathrm{Hb}$ (see Inline Supplementary Figure S3). All subsequent analyses were performed based on the results from the 49 subjects with successful segmentation.

Inline Supplementary Fig. S3 can be found online at http://dx.doi. org/10.1016/j.neuroimage.2016.01.048.

\section{Habenula-thalamus CNR}

The habenula-thalamus CNR ( $n=49)$ for T1w, T2w, and myelinsensitive images without bias field correction was $2.2 \pm 0.2,3.3 \pm 0.5$, and $5.4 \pm 1.0$ (mean \pm standard error), respectively (Fig. 7). Myelinsensitive images had significantly $(p<0.001)$ higher CNRs than T1w ( $250 \%$ ) or T2w (161\%) images. T2w images also had significantly higher CNRs than T1w images $(p<0.01,155 \%)$.

With bias field correction, the habenula-thalamus CNR $(n=49)$ for $\mathrm{T} 1 \mathrm{w}, \mathrm{T} 2 \mathrm{w}$, and myelin-sensitive images was $1.8 \pm 0.2,3.3 \pm 0.4$, and $4.7 \pm 0.7$, respectively. Overall, the bias field correction marginally changed the magnitude of the habenula-thalamus CNRs (see Inline Supplementary Figure S2). Nevertheless, the bias field correction significantly reduced the habenula-thalamus CNRs for T1w $\left(p<10^{-8}, 17 \%\right.$

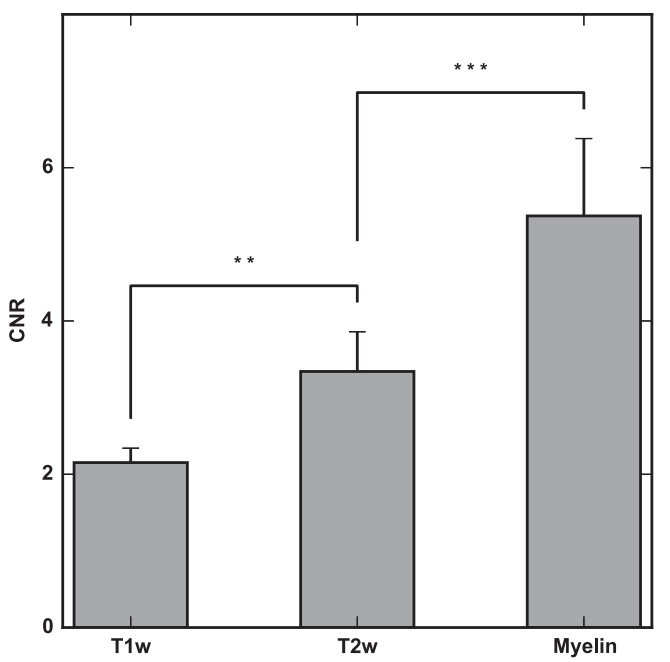

Fig. 7. Absolute values of the habenula-thalamus CNRs for $3 \mathrm{~T}$ in vivo $\mathrm{T} 1 \mathrm{w}, \mathrm{T} 2 \mathrm{w}$, and myelin-sensitive images, without bias field correction, from healthy HCP subjects $(n=$ 49). Error bars represent standard errors. ${ }^{* *} p<0.01$; ${ }^{* * *} p<0.001$. Note that the sign of the CNR value for T2w images was made positive in the figure for comparison.

decrease) and myelin-sensitive images ( $p<0.05,13 \%$ decrease) but did not have a significant effect on T2w images ( $p=0.9,1 \%$ decrease).

Inline Supplementary Fig. S2 can be found online at http://dx.doi. org/10.1016/j.neuroimage.2016.01.048.

\section{Myelin-sensitive image threshold constant $\alpha$}

The mean segmentation volume of all subjects at each segmentation step for various $\alpha$ values in Eq. (2) was evaluated (Fig. 8). There was a general negative correlation between $\alpha$ values and Hb volumes, particularly for the thresholded $\mathrm{Hb}$ regions (Histogram-based thresholding section). However, the region growing step noticeably reduced these negative correlations. The volume difference ratios of $\alpha=0.6$ to $\alpha=$ 1.0 , as an indicator of this negative correlation, reduced from 1.6 after the thresholding step to 1.2 after region growing step. The geometric constraints shifted the mean $\mathrm{Hb}$ volume down by about one standard error across all $\alpha$ values after removing overestimated voxels. As expected, the $H b$ segmentation with partial volume estimation is

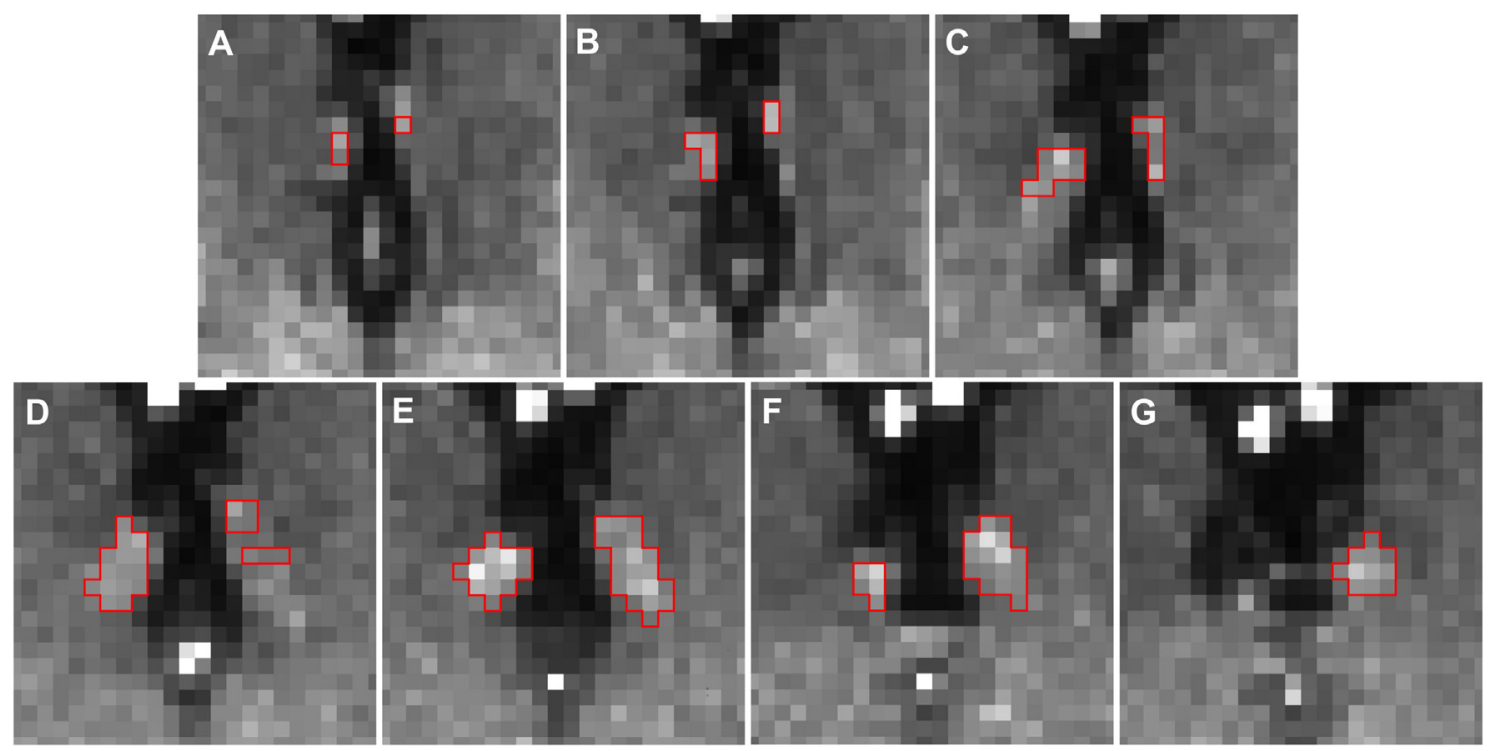

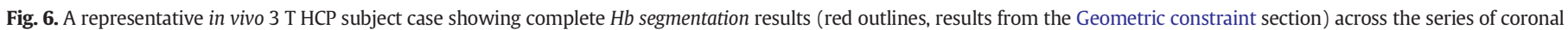
myelin-sensitive image slices, from anterior (A) to posterior $(G)$ 


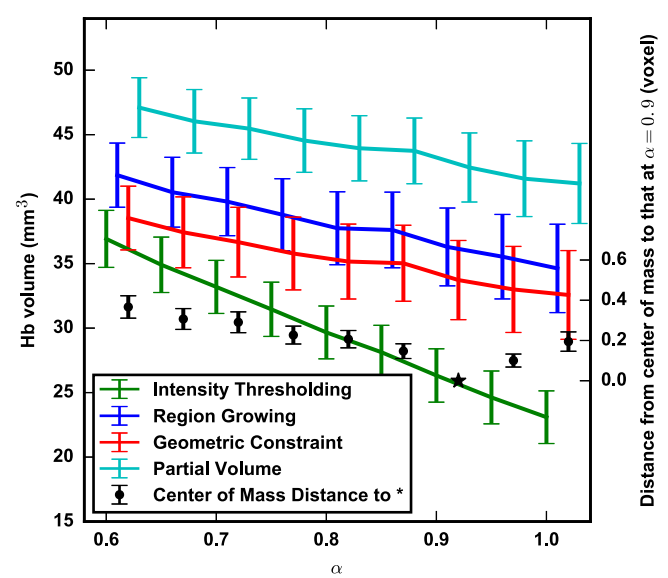

Fig. 8. In vivo $3 \mathrm{~T}$ mean Hb segmentation volumes $(n=49)$ decrease for increasing $\alpha$ values in Eq. (2). An empirical $\alpha$ value of 0.9 was chosen for all other evaluations in this manuscript. The mean Hb center of mass distances ( $y$ axis on the right of the figure) from $\alpha=0.9(\star)$ to other $\alpha$ values differ insignificantly. Error bars represent standard errors. Each color represents the results after applying the corresponding step in the legend, with all previous steps applied (as ordered from top to bottom in the legend except for the "Center of Mass Distance to $\star$ ").

substantially larger than the $\mathrm{Hb}$ segmentation because of the high proportion of boundary voxels.

The expert neuroanatomist (TPN) was not able to determine a preferred $\alpha$ value that consistently outperformed other $\alpha$ values across subjects, after inspection of the segmentation results. The centers of mass of the final $\mathrm{Hb}$ segmentation results were consistent across different $\alpha$ values (Fig. 8, black dots). The largest mean difference was 0.59 voxels between $\alpha=0.6$ and $\alpha=0.9$. Only three of the 49 subjects had $\alpha$-related $\mathrm{Hb}$ center of mass differences of more than two voxels.

\section{Effects of segmentation steps on segmented habenula volume}

Fixing $\alpha$ to 0.9 , the bilateral $\mathrm{Hb}$ volumes (mean \pm standard deviation, $n=49$ ) after the thresholding, region growing, geometric constraint, and partial volume estimation steps were $26.3 \pm 6.2,36.3 \pm$ 9.1, $33.7 \pm 9.2$ and $42.5 \pm 8.0 \mathrm{~mm}^{3}$, respectively (Fig. 9). For most subjects $(n=30)$, there were more significant segmentation changes between the thresholding step and the region growing step than any other steps. In approximately half of subjects $(n=25)$, the geometric constraints step effectively removed FR voxels wrongly assigned as $\mathrm{Hb}$ in the previous step, causing a decrease of more than $5 \%$ in the segmented volume. Finally, the partial volume estimation step increased the average volume by $26 \%$.

\section{Habenula volumes}

The $\mathrm{Hb}$ segmentation with partial volume estimation yielded (mean \pm standard deviation, $n=49$ ) a left $\mathrm{Hb}$ volume of $21.1 \pm 5.2 \mathrm{~mm}^{3}$ and a right $\mathrm{Hb}$ volume of $21.3 \pm 4.5 \mathrm{~mm}^{3}$. Manual segmentation of two ex vivo $\mathrm{Hb}$ tissue samples yielded left $\mathrm{Hb}$ volumes of $35.7 \mathrm{~mm}^{3}$ and $33.2 \mathrm{~mm}^{3}$ and right $\mathrm{Hb}$ volumes of $36.1 \mathrm{~mm}^{3}$ and $33.7 \mathrm{~mm}^{3}$. Manual segmentation of in vivo $7 \mathrm{~T}$ images $(n=6)$ yielded left $\mathrm{Hb}$ volumes of $18.3 \pm 2.3 \mathrm{~mm}^{3}$ and right $\mathrm{Hb}$ volumes of $17.9 \pm 2.1 \mathrm{~mm}^{3}$. The segmented left and right in vivo $3 \mathrm{~T} \mathrm{Hb}$ volumes were compared with those in the literature (Table 1): postmortem histology (Ranft et al., 2010) and in vivo T1w MR images with landmark-based (Lawson et al., 2013) or manual (Savitz et al., 2011b) segmentation; and manual segmentation results from in vivo $7 \mathrm{~T}$ and ex vivo MR images.

\section{Signal intensity correlations}

As expected, both T1w and T2w signal intensities were strongly pairwise correlated $(r \geq 0.65)$ between the $\mathrm{Hb}$, caudate, CSF, and CCs, with the exception of T1w signal intensity correlations between the CSF and the other regions due to the low T1w intensity in CSF. The myelin-sensitive image signal intensity in these regions all showed reduced pairwise correlations relative to the corresponding $\mathrm{T} 1 \mathrm{~W}$ and T2w signal intensity correlations, yielding moderate CSF-Hb $(r=$ $0.47)$, Hb-CCs $(r=0.40)$, and Hb-caudate $(r=0.56)$ correlation strengths (see Inline Supplementary Table S1; for individual line graphs see Inline Supplementary Figure S5A).

Inline Supplementary Table S1 can be found online at http://dx.doi. org/10.1016/j.neuroimage.2016.01.048.

\section{Gamma distribution}

The mean \pm standard deviation $(n=49)$ of $k$ and $\theta$ were $1.6 \pm 0.4$ and $0.8 \pm 0.4$, respectively, consistent with highly skewed but only moderately variable gamma distribution (see Inline Supplementary Figure S6).

Inline Supplementary Fig. S6 can be found online at http://dx.doi. org/10.1016/j.neuroimage.2016.01.048.
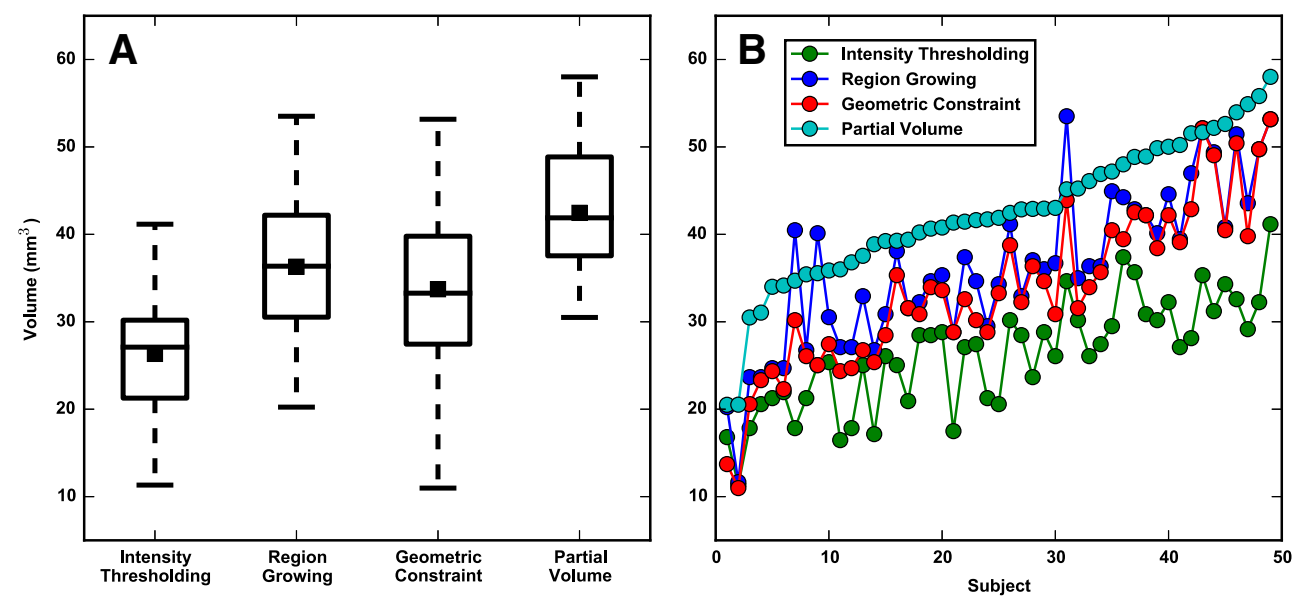

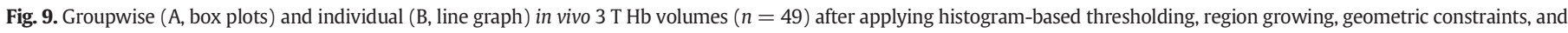

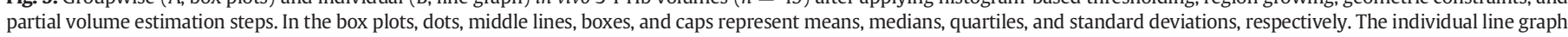
was sorted based on the $\mathrm{Hb}$ segmentation with partial volume estimation. 
Table 1

Summary of habenula volumes (mean \pm standard deviation) in the literature. LHb: lateral habenula; MHb: medial habenula.

\begin{tabular}{|c|c|c|c|c|}
\hline & $\begin{array}{l}\text { Ranft et al. (2010) } \\
\text { (postmortem histology), } \\
n=13\end{array}$ & $\begin{array}{l}\text { Lawson et al. (2013) } \\
\text { (in vivo T1w), } \\
n=24\end{array}$ & $\begin{array}{l}\text { Savitz et al. (2011b) } \\
\text { (in vivo T1w), } \\
n=74\end{array}$ & $\begin{array}{l}\text { This study } \\
\text { (in vivo T1w/T2w), } \\
n=49\end{array}$ \\
\hline Left $\mathrm{Hb}\left(\mathrm{mm}^{3}\right)$ & $\begin{array}{l}27.57 \pm 5.05(\mathrm{LHb}) \\
3.35 \pm 1.33(\mathrm{MHb})\end{array}$ & $31.6 \pm 5.0$ & $19.5 \pm 5.2$ & $21.1 \pm 5.2$ \\
\hline Right $\mathrm{Hb}\left(\mathrm{mm}^{3}\right)$ & $\begin{array}{l}29.59 \pm 4.83(\mathrm{LHb}) \\
3.64 \pm 0.97(\mathrm{MHb})\end{array}$ & $32.9 \pm 4.7$ & $17.0 \pm 4.7$ & $21.3 \pm 4.5$ \\
\hline
\end{tabular}

\section{MNI space transformation}

A probabilistic map of the $H b$ segmentation regions transformed to the standard MNI space is shown in Fig. 10. Excluding the lowest decile, the mean \pm standard deviation $(n=49)$ of the probabilities was $0.3 \pm$ 0.2. The MNI coordinates $(x, y, z)$ of the probability-weighted centers of mass were $(-2.7,-24.3,2.2)$ for the left $\mathrm{Hb}$ and $(4.0,-23.6,2.2)$ for the right $\mathrm{Hb}$. The MNI coordinates of the voxels with the maximum probability of being in the left Hb were $(-3.1,-25.2,1.5)$ and in the right $\mathrm{Hb}$ were $(3.9,-23.8,2.2)$. Voxels in the averaged $\mathrm{Hb}$ were located between 0 and $5.0 \mathrm{~mm}$ anterior to the PC, between -1.3 and $6.4 \mathrm{~mm}$ superior to the AC-PC line, between 1.0 and $5.2 \mathrm{~mm}$ left of the AC-PC line for the left $\mathrm{Hb}$, and between 2.5 and $6.0 \mathrm{~mm}$ right of the AC-PC line for the right $\mathrm{Hb}$. The principal axes (i.e., the eigenvector corresponding to the largest eigenvalue of the moment of inertia) of the averaged left and right $\mathrm{Hb}$ were $(-0.38,0.41,0.83)$ and $(0.30,0.51$, 0.81 ), respectively (Fig. 10D and F, dashed blue lines, respectively).

\section{Discussion}

In this study, we demonstrated an objective semi-automated $\mathrm{Hb}$ segmentation scheme to successfully segment the Hb region based on high-resolution $3 \mathrm{~T}$ in vivo $\mathrm{T} 1 \mathrm{w}$ and $\mathrm{T} 2 \mathrm{w}$ structural images. This segmentation scheme relies on the fact that the $\mathrm{Hb}$ has higher myelin content than the surrounding thalamus, which can be accentuated by generating myelin-sensitive images from the ratio of T1w to T2w images. These myelin-sensitive images have higher habenula-thalamus CNR than T1w or T2w image alone. When taking into account acquisition time (i.e., acquiring separate T1w and T2w images to generate myelin-sensitive images versus acquiring two T1 $w$ or T2w scans and averaging them to improve CNR, which takes a similar amount of scan time), the CNR of a repeated and averaged T2w image could approach those of a myelin-sensitive image. In practice, however, acquiring a T2w image without a T1w image is uncommon in neuroimaging studies and would limit the ability to utilize standard analysis pipelines. On the other hand, the addition of a high-resolution T2w image to the standard T1w image can not only enrich image contrast for subcortical structures but also be used to improve the robustness of pial surface generation (Glasser et al., 2013) for cortical myelin content mapping. Given the wide availability of T1 $\mathrm{w}$ and $\mathrm{T} 2 \mathrm{w}$ sequences on standard $3 \mathrm{~T}$ scanners, in our opinion, acquiring a pair of high-resolution T1w and T2w images is preferable to repeating either sequence for in vivo $3 \mathrm{~T}$ neuroimaging studies of the $\mathrm{Hb}$.

We chose not to correct for bias field as doing so slightly decreased the myelin-sensitive image CNR. This may be an effect of the spatial smoothing (FWHM $=5 \mathrm{~mm}$ ) applied to the bias field map (Glasser et al., 2013). Although we have not evaluated the effect of lower smoothing or using other bias field estimation algorithms, our findings suggest the final $\mathrm{Hb}$ segmentation results do not depend heavily on bias field correction.

The most highly myelinated portions of the $\mathrm{Hb}$ are concentrated on the stria medullaris (SM), lateral LHb, and FR, all of which border the dorsomedial thalamus from the dorsal anterior to ventral lateral part of the Hb (Díaz et al., 2011). This fact provides the histological basis for the proposed segmentation scheme to distinguish the $\mathrm{Hb}$ thalamus boundary more accurately than existing methods. Nevertheless, these highly myelinated areas do not entirely enclose the $\mathrm{Hb}$, especially toward the ventral posterior portion (Díaz et al., 2011), which requires additional geometric constraints based on anatomical landmarks for accurate segmentation (Geometric constraint section). It is also difficult to distinguish the exact boundary between the SM and dorsal lateral LHb, and between the lateral LHb and FR, even in histology (Fig. 5A-F). In fact, animal literature shows that certain myelinated fiber do not terminate at $\mathrm{Hb}$, but rather pass through the $\mathrm{Hb}$

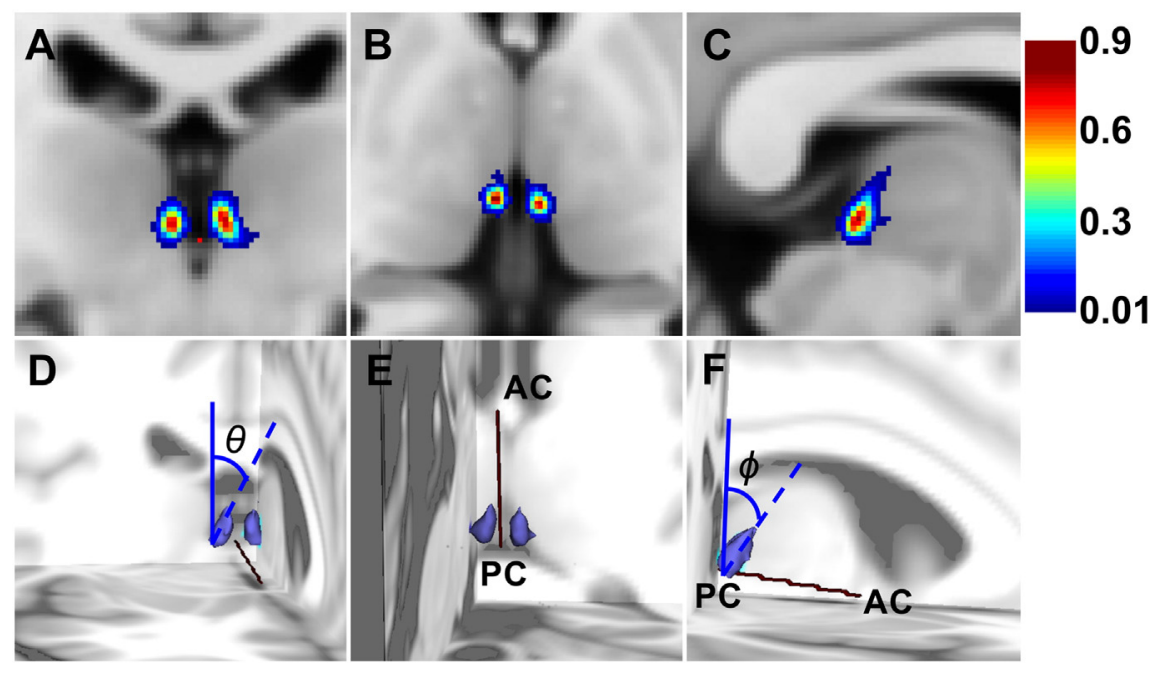

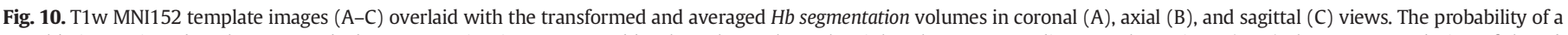

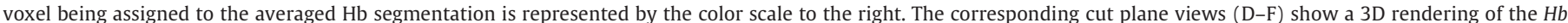

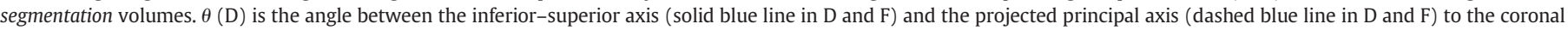

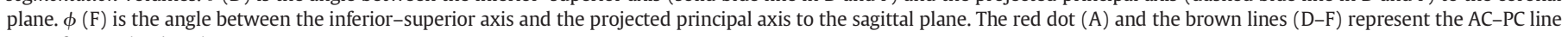
as a reference landmark. 
from the SM to the FR (Herkenham and Nauta, 1977). This fundamental limitation likely caused the one case of FR being mistakenly assigned as $\mathrm{Hb}$ in our $3 \mathrm{~T}$ in vivo cohort (see Inline Supplementary Figure S3). A robust and objective correction of such failed cases, either algorithmically or manually, would require better in vivo contrast between FR and $\mathrm{Hb}$ or a better understanding of the anatomical relationship between the FR and $\mathrm{Hb}$ through ex vivo imaging (Fig. $4 \mathrm{C}$ ).

The heterogeneous distribution and density of myelinated fibers within the $\mathrm{Hb}$ in histology (Díaz et al., 2011) resulted in a correspondingly heterogeneous PDw contrast in our ultra-high-resolution $(200 \mu \mathrm{m})$ ex vivo images (Fig. 5) and probably also accounts for the heterogenous quantitative T1 and T2* contrasts in a previous even higher resolution $(60 \mu \mathrm{m})$ ex vivo study (Strotmann et al., 2013). Despite this, our high-resolution (0.6-0.7 mm isotropic) in vivo $3 \mathrm{~T}$ (Fig. 1) and $7 \mathrm{~T}$ (Fig. 2) images did not clearly distinguish Hb subdivisions. This is most likely due to obfuscation of such subdivisions by partial volume effects, which may have been exacerbated by subjects' bulk and physiological motion (esp. CSF pulsation) in vivo. Nevertheless, we were able to detect a highly skewed intensity distribution within segmented $\mathrm{Hb}$ myelin-sensitive images in vivo (see Inline Supplementary Figure S6), consistent with the known internal heterogeneity of the $\mathrm{Hb}$.

One consequence of the heterogeneous myelin content in the $\mathrm{Hb}$ is expected to be a systematic bias toward highly myelinated portions of the $\mathrm{Hb}$ for any segmentation algorithm based primarily on anatomical image contrast. This bias will include both overestimation of the voxels bordering the SM (Fig. 9A) and FR (Fig. 9D-E), and underestimation of the voxels located at the ventral medial portion of the Hb. This observation, together with the small number of SM and FR voxels relative to the less myelinated voxels in the ventral medial $\mathrm{Hb}$, may account for why the in vivo $\mathrm{Hb}$ volumes reported here at $3 \mathrm{~T}$ and $7 \mathrm{~T}$ and previously reported elsewhere (Savitz et al., 2011a, 2011b) are consistently smaller than those we and others have reported ex vivo (Ranft et al., 2010). The implication of this myelination bias depends on what, if any, functional distinction exists between regions of high vs. low myelination within the $\mathrm{Hb}$, which remains an open question. It is worth noting that neurons of the human $\mathrm{Hb}$ are also heterogeneous in their morphological and cytochemical profiles (Díaz et al., 2011), which presumably reflects their complex functional roles. Correlating cellular features with the myelin content of the $\mathrm{Hb}$ in future studies will help inform the interpretation of in vivo $\mathrm{Hb}$ segmentation results from different approaches. Relatedly, the myelination bias of our segmentation scheme may enhance its sensitivity to possible degeneration of $\mathrm{Hb}$ neurons and/or efferent axons in psychiatric disorders, such as have been reported in animal models of substance abuse (Ellison, 1992; Lax et al., 2013). However, further study of psychiatric populations is needed to ascertain the extent to which such degeneration, if present in human, reduces $\mathrm{Hb}$ image contrast and therefore the reliability of our segmentation scheme.

The proposed $\mathrm{Hb}$ segmentation scheme is objective (i.e., free from manual delineation of the $\mathrm{Hb}$ ), despite a few thresholding criteria used in each segmentation step, chosen based on a combination of established literature, histological evidence, reference atlases, and empirical testing. Indeed, the resulting $\mathrm{Hb}$ segmentation volume depends on the myelin-sensitive image threshold constant $\alpha$ (Myelin-sensitive image threshold constant $\alpha$ section). Higher $\alpha$ values define smaller $\mathrm{Hb}$ volumes and vice versa. Encouragingly, all segmentation results were reasonable according to the expert neuroanatomist (TPN) and the $\mathrm{Hb}$ centers of mass in our study were consistent over a range of $\alpha$ values (Fig. 7, black) despite this threshold value dependency. Moreover, the variation in center of mass $(n=49)$ was less than two anatomical voxels $(<1.4 \mathrm{~mm})$, making it sufficiently small to have little or no effect on placement of seed voxels in fMRI or dMRI studies (typically $\geq 1.5 \mathrm{~mm}$ isotropic resolution at $3 \mathrm{~T}$ ). Hence, our segmentation scheme provides a robust, objective, and anatomically grounded approach for selecting $\mathrm{Hb}$ seed voxels for fMRI and dMRI application (Shelton et al., 2012; Strotmann et al., 2014; Lawson et al., 2014;
Hennigan et al., 2015; Erpelding et al., 2014; Ely et al., under revision). For $\mathrm{Hb}$ morphological studies, the choice of the optimal $\alpha$ value may depend on image resolution and/or image contrast, which will need to be explored further.

The average MNI-transformed centers of mass of the left $(-2.7$, $-24.3,2.2)$ and right $(4.0,-23.6,2.2) \mathrm{Hb}$ in our study are very close to those previously reported by Lawson et al. (left $\mathrm{Hb}$ : $-2.8,-24.4$, 2.3; right $\mathrm{Hb}: 4.8,-24.1,2.2$ ). These highly concordant results from two independent approaches demonstrate the reliability of groupwise $\mathrm{Hb}$ seeding for fMRI studies. Despite this group-level center of mass correspondence, our study also reveals high variance in individual $\mathrm{Hb}$ boundaries following transformation to MNI space (MNI space transformation section), indicating additional challenges for optimal group-level averaging and structural-to-functional MRI space transformation for this region.

We speculate that our segmentation scheme based on myelin contrast is more sensitive to individual $\mathrm{Hb}$ morphological variability than the existing $\mathrm{Hb}$ segmentation methods, which is important for detecting neurobiological changes in $\mathrm{Hb}$ in psychiatric disorders. Compared to manual segmentation based on T1w contrast (Savitz et al., 2011b), our signal intensity correlation results (Signal intensity correlations section) suggest that myelin-sensitive image intensity is less prone to systematic signal variation. Hence, our segmentation results are likely less prone to systematic bias than those by manual segmentation despite the low intra/interrater variability achievable from the latter. Additionally, the fact that our segmentation scheme is entirely based on local MR signal properties and includes an estimation of partial volume effects makes our method more appropriate for individual $\mathrm{Hb}$ morphological analysis than geometric landmark-based Hb segmentation methods (Lawson et al., 2013).

To achieve consistent and objective $\mathrm{Hb}$ segmentation results in our scheme, prior knowledge about the morphology of the $\mathrm{Hb}$, based on histology and other literature (Díaz et al., 2011; Mai et al., 2007; Hawrylycz et al., 2012), was used for generating the Hb shaped template ROI (Histogram-based thresholding section), which require AC-PC alignment. Similarly, our geometric constraints (Geometric constraint section) are dependent on AP-PC aligned coronal slices. Hence, we recommend users apply the current software implementation (github version 1.0) of the segmentation scheme only on AC-PC aligned images.

In addition to the $0.7 \mathrm{~mm}$ isotropic resolution $\mathrm{HCP}$ structural images, we have also successfully applied the algorithm to structural data at 0.8 and $0.9 \mathrm{~mm}$ isotropic resolutions acquired from a standard $3 \mathrm{~T}$ clinical scanner (see Inline Supplementary Figures S7 and S8). These results are encouraging and suggest a certain degree of consistency and reliability of the proposed segmentation scheme, although a systematic evaluation across in vivo structural image resolution is beyond the scope of this study.

Inline Supplementary Figs. S7 and S8 can be found online at http:// dx.doi.org/10.1016/j.neuroimage.2016.01.048.

Recently, quantitative T1 mapping has shown great promise for elucidating cortical myelin content (Sereno et al., 2013; Geyer et al., 2011; Lutti et al., 2014), especially with the ultra-high-resolution afforded at $7 \mathrm{~T}$ (Bazin et al., 2014) and the ever-increasing availability of optimized T1 mapping acquisition protocols at $7 \mathrm{~T}$ (Marques and Gruetter, 2013). Indeed, a recent study used $\mathrm{T} 1$ mapping, together with T2* mapping, to study the $\mathrm{Hb}$ with $0.8 \mathrm{~mm}$ isotropic in vivo resolution at $7 \mathrm{~T}$ (Strotmann et al., 2014). Strotmann et al. concluded that the low $\mathrm{T} 1$ value of the $\mathrm{Hb}$ was due to the unusually large number of myelinated fibers, whereas its low T2* value was the result of high iron content; these inferences were based on a quantitative ex vivo study of the contributions of myelin and iron to MRI contrast mechanisms (Stüber et al., 2014). Although we agree with Strotmann et al. regarding the effect of myelination on $\mathrm{Hb}$ T1 values on the basis of histological evidence (Díaz et al., 2011), we remain cautious about their interpretation of iron as the source of the reduced $\mathrm{Hb} \mathrm{T2}^{*}$ value given that the cellular composition of the $\mathrm{Hb}$ is neither similar to cortical gray matter nor to iron-rich deep gray matter nuclei (e.g., the subthalamic nucleus, 
Stüber et al., 2014). To the best of our knowledge, direct histological evidence regarding the iron content of the $\mathrm{Hb}$ has not yet been reported, making this a topic of great interest for future research. Relevant to the focus of the current study, we note the need for an objective automated $\mathrm{Hb}$ segmentation method for quantitative imaging remains the same as for non-quantitative imaging, so does further work addressing the aforementioned limitations (e.g., myelination bias) of our proposed $\mathrm{Hb}$ segmentation scheme for either quantitative or nonquantitative imaging. While quantitative mapping has many advantages (e.g., longitudinal comparison, multi-site studies, etc.) over qualitative anatomical imaging, it is beyond the scope of this study to compare $\mathrm{Hb}$ segmentation results based on qualitative myelin-sensitive images with quantitative $\mathrm{T} 1$ and/or T2* mapping. We speculate that $\mathrm{Hb}$ localization (i.e., center of mass) results would be comparable across these segmentation methods, while it remains a challenge to assess the segmentation accuracy of the $\mathrm{Hb}$ boundaries against the ground-truth histology.

As demonstrated by our $7 \mathrm{~T}$ results (Fig. 2) and by Strotmann et al. (2014), and possibly in other publicly available $7 \mathrm{~T}$ data (Forstmann et al., 2014), better in vivo contrast is possible at $7 \mathrm{~T}$ for $\mathrm{Hb}$ due to the higher spatial resolution than can be achieved at $3 \mathrm{~T}$. Of note, however, we observed prominent venous vessel artifacts around the $\mathrm{Hb}$ region in the $\mathrm{T} 2^{*} \mathrm{w}$ images used to generate our in vivo $7 \mathrm{~T}$ myelin-sensitive images (see Inline Supplementary Figure S4, green arrow), which may limit the use of $\mathrm{T} 2 * \mathrm{w}$ images for reliable $\mathrm{Hb}$ contrast on $7 \mathrm{~T}$ data. For this reason, we did not attempt to adapt our segmentation scheme to the $7 \mathrm{~T}$ myelin-sensitive images presented in this study. Nevertheless, high-resolution and high contrast $7 \mathrm{~T} \mathrm{Hb}$ imaging (Strotmann et al., 2014) and associated objective $7 \mathrm{~T} \mathrm{Hb}$ segmentation schemes represent a promising future research direction for more accurate $\mathrm{Hb}$ morphological and functional evaluation.

\section{Conclusions}

We have successfully implemented an objective semi-automated $\mathrm{Hb}$ segmentation scheme for in vivo $3 \mathrm{~T} \mathrm{~T} 1 \mathrm{w}$ and $\mathrm{T} 2 \mathrm{w}$ images. The segmentation scheme relies mainly on the improved CNR of myelin-sensitive images (i.e., $\mathrm{T} 1 \mathrm{w}$ over $\mathrm{T} 2 \mathrm{w}$ ratio images) due to the higher myelin content in the $\mathrm{Hb}$ than the surrounding thalamus. In addition, in vivo $7 \mathrm{~T}$ myelin-sensitive images and ex vivo PDw images, along with histological evidence from the literature, strongly corroborated our in vivo $3 \mathrm{~T} \mathrm{Hb}$ myelin contrast. The proposed segmentation scheme represents a step toward a scalable approach for objective $\mathrm{Hb}$ segmentation, suitable for both morphological evaluation and fMRI applications. Future investigation is needed to evaluate the reproducibility of the proposed segmentation scheme under various acquisition and contrast conditions.

\section{Acknowledgment}

Data were provided (in part) by the Human Connectome Project, WU-Minn Consortium (Principal Investigators: David Van Essen and Kamil Ugurbil; 1U54MH091657) funded by the $16 \mathrm{NIH}$ Institutes and Centers that support the NIH Blueprint for Neuroscience Research and by the McDonnell Center for Systems Neuroscience at Washington University. We would like to thank the Brain Imaging Center (BIC) at Icahn School of Medicine at Mount Sinai for purchasing the HCP Connetomein-a-Box data.

\section{Conflict of interests}

The authors declare no competing financial interests.

\section{Funding}

FDM was supported by NWO VIDI grant 864-13-012; WG was supported by Simons Foundation grant SFARI 277909 for lateral $\mathrm{Hb}$
DBS in treatment-resistant depression (ClinicalTrials.gov identifier: NCT01798407); JX was supported by Radiological Society of North America (RSNA) research scholar grant RSCH1328 and Brain and Behavior Research Foundation (BBRF) young investigator grant NARSAD22324.

\section{Appendix A. Initial ROI}

Let $v_{0}$ be the seed voxel for the Hb. Then the radius $l$ of the initial ROI is the smallest integer satisfying

$\left|\left\{v \mid d\left(v, v_{0}\right) \leq l\right\}\right|>V_{\text {init }}$

where $v$ is a voxel, $d\left(v, v_{0}\right)$ is the $L_{1}$-norm distance (i.e., sum of the absolute coordinate distance for each axis) in voxel unit, and $V_{\text {init }}$ is a minimum volume for ROI (e.g., $V_{\text {init }}=300$ voxels, $l=7$ in this work to include a sufficient number of voxels surrounding the $\mathrm{Hb}$ ). $L_{1}$-norm distance was used because of the relatively round shape of $\mathrm{Hb}$ and computational simplicity. $V_{\text {init }}$ and $l$ can be changed depending on image resolution.

\section{Appendix B. ROI template}

Human $\mathrm{Hb}$ shapes are usually of a skewed sphere with the superior $\mathrm{Hb}$ regions centered more medially (Fig. $10 \mathrm{D}, \theta \cong 23^{\circ}$ ) and anteriorly (Fig. 10F, $\phi \cong 29^{\circ}$ ) than the inferior $\mathrm{Hb}$ regions (Fig. 10). To create an ROI template representing this shape, we defined a set of voxels satisfying

$$
\left\{\begin{array}{c}
\frac{x^{2}}{a^{2}}+\frac{y^{2}}{b^{2}}+\frac{z^{2}}{c^{2}} \leq 1, \quad z<0 \\
\frac{(x-z / 2)^{2}}{a^{2}}+\frac{(y-z / 2)^{2}}{b^{2}}+\frac{z^{2}}{c^{2}} \leq 1, \quad z \geq 0 \text { for right } \mathrm{Hb} \\
\frac{(x+z / 2)^{2}}{a^{2}}+\frac{(y-z / 2)^{2}}{b^{2}}+\frac{z^{2}}{c^{2}} \leq 1, \quad z \geq 0 \text { for left } \mathrm{Hb}
\end{array}\right.
$$

where $x, y$, and $z$ are right-left, posterior-anterior, and inferior-superior coordinates, respectively, centered at the center of mass of previously segmented $\mathrm{Hb}$. Note that $x \pm z / 2$ and $y-z / 2$ move the centers of ellipses to medial and anterior as $z$ moves superiorly.

\section{Appendix C. Geometric constraint-lateral limit}

We define a function $M(x)=\max _{y}\{y \mid(x, y) \in H\}$ on each coronal slice, where $H$ is the segmented $H b$ and $(x, y)$ represents (left-right, inferior-superior) coordinates. Our criterion is that the function $M(x)$, representing the $y$ coordinate of the most superior voxel for column $x$, should monotonically decrease as $x$ goes from medial to lateral. When it does not monotonically decrease after $x_{0}$, in other words, when $M\left(x_{0}\right)<M\left(x_{1}\right)$ where $x_{1}$ is more lateral than $x_{0}$, then $x_{0}$ is the lateral limit of $\mathrm{Hb}$ (Fig. 3E, black lines).

\section{References}

Aizawa, H., Amo, R., Okamoto, H., 2011. Phylogeny and ontogeny of the habenular structure. Front Neurosci. 5, 138. http://dx.doi.org/10.3389/fnins.2011.00138.

Bazin, P.-L., Weiss, M., Dinse, J., Schäfer, A., Trampel, R., Turner, R., 2014. A computational framework for ultra-high resolution cortical segmentation at 7 Tesla. Neurolmage 93 (Pt 2), 201-209. http://dx.doi.org/10.1016/j.neuroimage.2013.03.077.

Bianco, I.H., Wilson, S.W., 2009. The habenular nuclei: a conserved asymmetric relay station in the vertebrate brain. Philos. Trans. R. Soc. Lond. B Biol. Sci. 364, 1005-1020. http://dx.doi.org/10.1098/rstb.2008.0213.

Carceller-Sindreu, M., de Diego-Adeliño, J., Serra-Blasco, M., Vives-Gilabert, Y., Martí NBlanco, A., Puigdemont, D., Álvarez, E., Pérez, V., Portella, M.J., 2015. Volumetric MRI study of the habenula in first episode, recurrent and chronic major depression. Eur. Neuropsychopharmacol. http://dx.doi.org/10.1016/j.euroneuro.2015.08.009.

De Martino, F., Moerel, M., Xu, J., van de Moortele, P.-F., Ugurbil, K., Goebel, R., Yacoub, E., Formisano, E., 2015. High-resolution mapping of myeloarchitecture in vivo: localization of auditory areas in the human brain. Cereb. Cortex 25, 3394-3405. http://dx.doi. org/10.1093/cercor/bhu150. 
Díaz, E., Bravo, D., Rojas, X., Concha, M.L., 2011. Morphologic and immunohistochemical organization of the human habenular complex. J. Comp. Neurol. 519, 3727-3747. http://dx.doi.org/10.1002/cne.22687.

Ellison, G., 1992. Continuous amphetamine and cocaine have similar neurotoxic effects in lateral habenular nucleus and fasciculus retroflexus. Brain Res. 598, 353-356.

Ely, B.A., Xu, J., Goodman, W.K., Lapidus, K.A., Gabbay, V., Stern, E.R., 2016. Resting-State Functional Connectivity of the Human Habenula in Healthy Individuals: Associations with Subclinical Depression. Hum. Brain Mapp. (under revision).

Erpelding, N., Sava, S., Simons, L.E., Lebel, A., Serrano, P., Becerra, L., Borsook, D., 2014. Habenula functional resting-state connectivity in pediatric CRPS. J. Neurophysiol. 111, 239-247. http://dx.doi.org/10.1152/jn.00405.2013.

Forstmann, B.U., Keuken, M.C., Schafer, A., Bazin, P.-L., Alkemade, A., Turner, R., 2014. Multi-modal ultra-high resolution structural 7-Tesla MRI data repository. Sci. Data 1, 140050. http://dx.doi.org/10.1038/sdata.2014.50.

Geisler, S., Trimble, M., 2008. The lateral habenula: no longer neglected. CNS Spectr. 13, 484-489. http://dx.doi.org/10.1017/S1092852900016710.

Geyer, S., Weiss, M., Reimann, K., Lohmann, G., Turner, R., 2011. Microstructural parcellation of the human cerebral cortex-from Brodmann's post-mortem map to in vivo mapping with high-field magnetic resonance imaging. Front. Hum. Neurosci. 5. http://dx.doi.org/10.3389/fnhum.2011.00019.

Glasser, M.F., Van Essen, D.C., 2011. Mapping human cortical areas in vivo based on myelin content as revealed by T1- and T2-weighted MRI. J. Neurosci. Off. J. Soc. Neurosci. 31, 11597-11616. http://dx.doi.org/10.1523/JNEUROSCI.2180-11.2011.

Glasser, M.F., Sotiropoulos, S.N., Wilson, J.A., Coalson, T.S., Fischl, B., Andersson, J.L., Xu, J., Jbabdi, S., Webster, M., Polimeni, J.R., Van Essen, D.C., Jenkinson, M., WU-Minn HCP Consortium, 2013. The minimal preprocessing pipelines for the Human Connectome Project. NeuroImage 80, 105-124. http://dx.doi.org/10.1016/j.neuroimage.2013.04. 127.

Glasser, M.F., Goyal, M.S., Preuss, T.M., Raichle, M.E., Van Essen, D.C., 2014. Trends and properties of human cerebral cortex: Correlations with cortical myelin content. Neuroimage 93 (Part 2), 165-175. http://dx.doi.org/10.1016/j.neuroimage.2013.03. 060 (In-vivo Brodmann Mapping of the Human Brain).

Hawrylycz, M.J., Lein, E.S., Guillozet-Bongaarts, A.L., Shen, E.H., Ng, L., Miller, J.A., van de Lagemaat, L.N., Smith, K.A., Ebbert, A., Riley, Z.L., Abajian, C., Beckmann, C.F., Bernard, A., Bertagnolli, D., Boe, A.F., Cartagena, P.M., Chakravarty, M.M., Chapin, M., Chong, J., Dalley, R.A., Daly, B.D., Dang, C., Datta, S., Dee, N., Dolbeare, T.A., Faber, V. Feng, D., Fowler, D.R., Goldy, J., Gregor, B.W., Haradon, Z., Haynor, D.R., Hohmann, J.G., Horvath, S., Howard, R.E., Jeromin, A., Jochim, J.M., Kinnunen, M., Lau, C., Lazarz, E.T., Lee, C., Lemon, T.A., Li, L., Li, Y., Morris, J.A., Overly, C.C., Parker, P.D., Parry, S.E., Reding, M., Royall, J.J., Schulkin, J., Sequeira, P.A., Slaughterbeck, C.R., Smith, S.C., Sodt, A.J., Sunkin, S.M., Swanson, B.E., Vawter, M.P., Williams, D., Wohnoutka, P., Zielke, H.R., Geschwind, D.H., Hof, P.R., Smith, S.M., Koch, C., Grant, S.G.N., Jones, A.R., 2012. An anatomically comprehensive atlas of the adult human brain transcriptome. Nature 489, 391-399. http://dx.doi.org/10.1038/nature11405.

Hennigan, K., D'Ardenne, K., McClure, S.M., 2015. Distinct midbrain and habenula pathways are involved in processing aversive events in humans. J. Neurosci. 35, 198-208. http://dx.doi.org/10.1523/JNEUROSCI.0927-14.2015.

Herkenham, M., Nauta, W.J., 1977. Afferent connections of the habenular nuclei in the rat. A horseradish peroxidase study, with a note on the fiber-of-passage problem. J. Comp. Neurol. 173, 123-146. http://dx.doi.org/10.1002/cne.901730107.

Hikosaka, O., 2010. The habenula: from stress evasion to value-based decision-making. Nat. Rev. Neurosci. 11, 503-513. http://dx.doi.org/10.1038/nrn2866.

Hikosaka, O., Sesack, S.R., Lecourtier, L., Shepard, P.D., 2008. Habenula-crossroad between the Basal Ganglia and the Limbic System. J. Neurosci. Off. J. Soc. Neurosci. 28, 11825-11829. http://dx.doi.org/10.1523/JNEUROSCI.3463-08.2008.

Kiening, K., Sartorius, A., 2013. A new translational target for deep brain stimulation to treat depression. EMBO Mol. Med. 5, 1151-1153. http://dx.doi.org/10.1002/emmm. 201302947.

Kim, U., 2009. Topographic commissural and descending projections of the habenula in the rat. J. Comp. Neurol. 513, 173-187. http://dx.doi.org/10.1002/cne.21951.

Lawson, R.P., Drevets, W.C., Roiser, J.P., 2013. Defining the habenula in human neuroimaging studies. NeuroImage 64, 722-727. http://dx.doi.org/10.1016/j.neuroimage.2012. 08.076.

Lawson, R.P., Seymour, B., Loh, E., Lutti, A., Dolan, R.J., Dayan, P., Weiskopf, N., Roiser, J.P., 2014. The habenula encodes negative motivational value associated with primary punishment in humans. Proc. Natl. Acad. Sci. U. S. A. 111, 11858-11863. http://dx. doi.org/10.1073/pnas.1323586111.

Lax, E., Friedman, A., Croitoru, O., Sudai, E., Ben-Moshe, H., Redlus, L., Sasson, E. Blumenfeld-Katzir, T., Assaf, Y., Yadid, G., 2013. Neurodegeneration of lateral habenula efferent fibers after intermittent cocaine administration: implications for deep brain stimulation. Neuropharmacology 75, 246-254. http://dx.doi.org/10. 1016/j.neuropharm.2013.06.034.

Lutti, A., Dick, F., Sereno, M.I., Weiskopf, N., 2014. Using high-resolution quantitative mapping of R1 as an index of cortical myelination. Neurolmage 93 (Pt 2), 176-188. http:// dx.doi.org/10.1016/j.neuroimage.2013.06.005.
Mai, J.K., Paxinos, G., Voss, T., 2007. Atlas of the Human Brain. 3rd ed.

Marques, J.P., Gruetter, R., 2013. New developments and applications of the MP2RAGE sequence-focusing the contrast and high spatial resolution R1 mapping. PLoS ONE 8. http://dx.doi.org/10.1371/journal.pone.0069294.

Matsumoto, M., Hikosaka, O., 2007. Lateral habenula as a source of negative reward signals in dopamine neurons. Nature 447, 1111-1115. http://dx.doi.org/10.1038/nature05860.

Matsumoto, M., Hikosaka, O., 2009. Representation of negative motivational value in the primate lateral habenula. Nat. Neurosci. 12, 77-84. http://dx.doi.org/10.1038/nn. 2233.

Meye, F.J., Lecca, S., Valentinova, K., Mameli, M., 2013. Synaptic and cellular profile of neurons in the lateral habenula. Front. Hum. Neurosci. 7, 860. http://dx.doi.org/10.3389/ fnhum.2013.00860.

Nishikawa, T., Fage, D., Scatton, B., 1986. Evidence for, and nature of, the tonic inhibitory influence of habenulointerpeduncular pathways upon cerebral dopaminergic transmission in the rat. Brain Res. 373, 324-336.

Proulx, C.D., Hikosaka, O., Malinow, R., 2014. Reward processing by the lateral habenula in normal and depressive behaviors. Nat. Neurosci. 17, 1146-1152. http://dx.doi.org/10. 1038/nn.3779.

R Core Team, 2015. R: A Language and Environment for Statistical Computing. R Foundation for Statistical Computing, Vienna, Austria.

Ranft, K., Dobrowolny, H., Krell, D., Bielau, H., Bogerts, B., Bernstein, H.-G., 2010. Evidence for structural abnormalities of the human habenular complex in affective disorders but not in schizophrenia. Psychol. Med. 40, 557-567. http://dx.doi.org/10.1017/ S0033291709990821.

Riley, H.A., 1943. Atlas of the Basal Ganglia, Brain Stem and Spinal Cord Based on MyelinStained Material. First edition. Williams \& Wilkins.

Sartorius, A., Henn, F.A., 2007. Deep brain stimulation of the lateral habenula in treatment resistant major depression. Med. Hypotheses 69, 1305-1308. http://dx.doi.org/10. 1016/j.mehy.2007.03.021.

Sartorius, A., Kiening, K.L., Kirsch, P., von Gall, C.C., Haberkorn, U., Unterberg, A.W., Henn, F.A., Meyer-Lindenberg, A., 2010. Remission of major depression under deep brain stimulation of the lateral habenula in a therapy-refractory patient. Biol. Psychiatry 67, e9-e11. http://dx.doi.org/10.1016/j.biopsych.2009.08.027.

Savitz, J.B., Bonne, O., Nugent, A.C., Vythilingam, M., Bogers, W., Charney, D.S., Drevets, W.C., 2011a. Habenula volume in post-traumatic stress disorder measured with high-resolution MRI. Biol. Mood Anxiety Disord. 1, 7. http://dx.doi.org/10.1186/ 2045-5380-1-7.

Savitz, J.B., Nugent, A.C., Bogers, W., Roiser, J.P., Bain, E.E., Neumeister, A., Zarate, C.A., Manji, H.K., Cannon, D.M., Marrett, S., Henn, F., Charney, D.S., Drevets, W.C., 2011b. Habenula volume in bipolar disorder and major depressive disorder: a highresolution magnetic resonance imaging study. Biol. Psychiatry 69, 336-343. http:// dx.doi.org/10.1016/j.biopsych.2010.09.027.

SciPy, 2001. Open source scientific tools for Python.

Sereno, M.I., Lutti, A., Weiskopf, N., Dick, F., 2013. Mapping the human cortical surface by combining quantitative T1 with retinotopy. Cereb. Cortex 23, 2261-2268. http://dx. doi.org/10.1093/cercor/bhs213.

Shafee, R., Buckner, R.L., Fischl, B., 2015. Gray matter myelination of 1555 human brains using partial volume corrected MRI images. Neurolmage 105, 473-485. http://dx. doi.org/10.1016/j.neuroimage.2014.10.054.

Shelton, L., Pendse, G., Maleki, N., Moulton, E.A., Lebel, A., Becerra, L., Borsook, D., 2012. Mapping pain activation and connectivity of the human habenula. J. Neurophysiol. 107, 2633-2648. http://dx.doi.org/10.1152/jn.00012.2012

Strotmann, B., Kögler, C., Bazin, P.-L., Weiss, M., Villringer, A., Turner, R., 2013. Mapping of the internal structure of human habenula with ex vivo MRI at 7T. Front. Hum. Neurosci. 7. http://dx.doi.org/10.3389/fnhum.2013.00878.

Strotmann, B., Heidemann, R.M., Anwander, A., Weiss, M., Trampel, R., Villringer, A. Turner, R., 2014. High-resolution MRI and diffusion-weighted imaging of the human habenula at 7 tesla. J. Magn. Reson. Imaging 39, 1018-1026. http://dx.doi org/10.1002/jmri.24252.

Stüber, C., Morawski, M., Schäfer, A., Labadie, C., Wähnert, M., Leuze, C., Streicher, M. Barapatre, N., Reimann, K., Geyer, S., Spemann, D., Turner, R., 2014. Myelin and iron concentration in the human brain: a quantitative study of MRI contrast. Neurolmage 93 (Pt 1), 95-106. http://dx.doi.org/10.1016/j.neuroimage.2014.02.026.

Van Essen, D.C., Ugurbil, K., Auerbach, E., Barch, D., Behrens, T.E.J., Bucholz, R., Chang, A. Chen, L., Corbetta, M., Curtiss, S.W., Della Penna, S., Feinberg, D., Glasser, M.F., Harel, N., Heath, A.C., Larson-Prior, L., Marcus, D., Michalareas, G., Moeller, S., Oostenveld R., Petersen, S.E., Prior, F., Schlaggar, B.L., Smith, S.M., Snyder, A.Z., Xu, J., Yacoub, E. WU-Minn HCP Consortium, 2012. The Human Connectome Project: a data acquisition perspective. Neurolmage 62, 2222-2231. http://dx.doi.org/10.1016/j.neuroimage. 2012.02.018.

Viswanath, H., Carter, A.Q., Baldwin, P.R., Molfese, D.L., Salas, R., 2014. The media habenula: still neglected. Front. Hum. Neurosci. 7, 931. http://dx.doi.org/10.3389/ fnhum.2013.00931. 